\title{
Comparison of Conventional and Cone Beam CT synthesized Cephalograms
}

\section{By}

\section{Vandana Kumar}

A thesis submitted to the faculty of the University of North Carolina at Chapel Hill in partial

fulfillment of the requirements for the degree of Master of Science in the Department of Diagnostic Sciences and General Dentistry, School of Dentistry.

\section{Chapel Hill}

2007

Approved by:

Advisor: Dr. John Ludlow DDS, MS, FDS RCSEd

Reader: Dr. André Mol. DDS, MS, PhD

Reader: Dr. Lucia Cevidanes DDS, PhD 


\begin{abstract}
Vandana Kumar

"In vitro Comparison of Conventional and Cone Beam Synthesized Cephalograms"

(Part I), and "In vivo Comparison of Conventional and Cone Beam Synthesized

Cephalograms utilizing patient data" (Part II)

(Under the direction of Dr John Ludlow)
\end{abstract}

The purpose of this study was to determine whether Cone Beam Computed Tomography (CBCT) synthesized cephalograms provide the same measurement accuracy and precision as conventional cephalograms. In Part I, cephalometric measurements of conventional and CBCT synthesized orthogonal or perspective projections of 10 skulls were compared with each other and with the actual skull measurements. In Part II, actual patient data was used to compare the three imaging modalities and both soft and hard tissue landmarks were utilized.

This study demonstrated that most cephalometric measurements are not different for conventional and $\mathrm{CBCT}$ synthesized orthogonal and the perspective projections. Although there is a statically significant difference between mid-sagittal image measurements compared to actual skull measurements, these differences are very small and are unlikely to have clinical relevance. Both of the projections can be used with an expectation of precision and accuracy similar to conventional cephalograms. 


\section{TABLE OF CONTENTS}

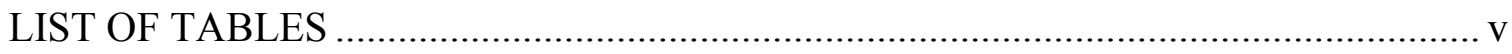

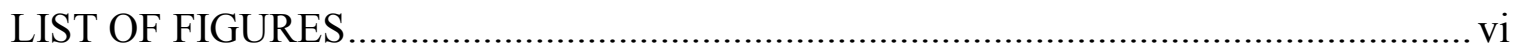

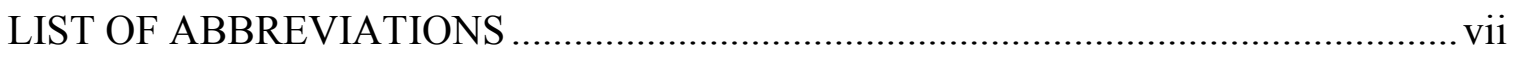

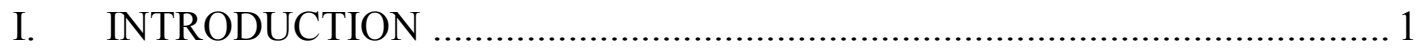

II. MANUSCRIPT I - "In vitro Comparison of Conventional and Cone Beam Synthesized Cephalograms"......................................................... 6

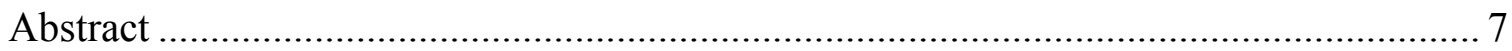

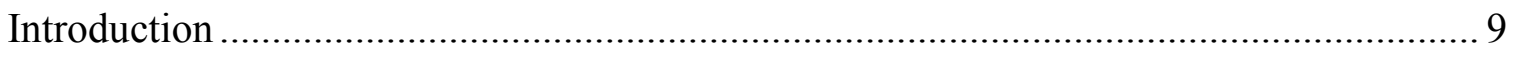

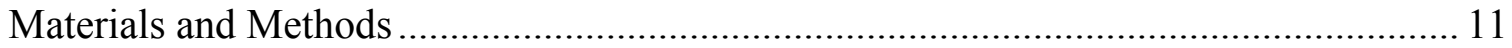

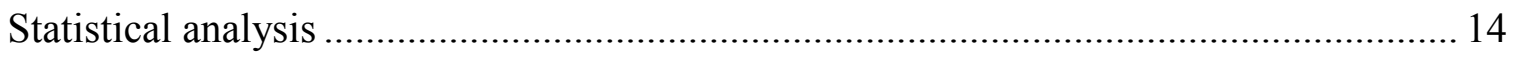

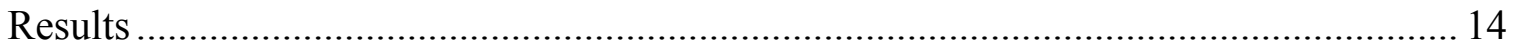

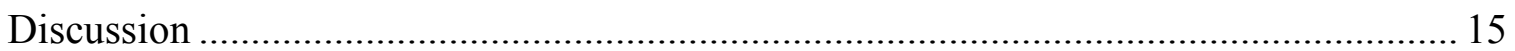

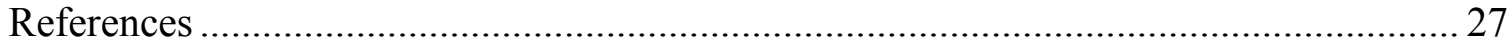

III. MANUSCRIPT II - "In vivo Comparison of Conventional and Cone Beam Synthesized Cephalograms...................................................... 29

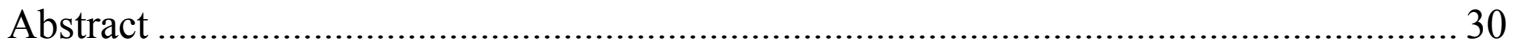

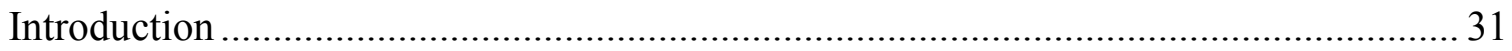

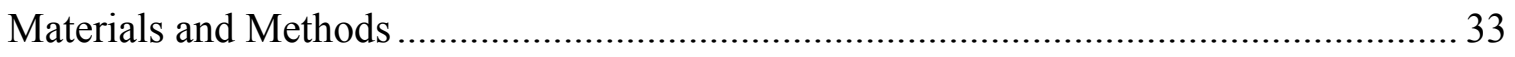

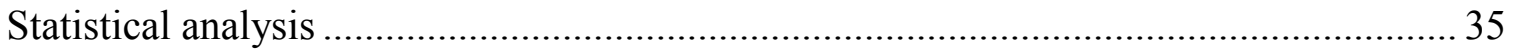

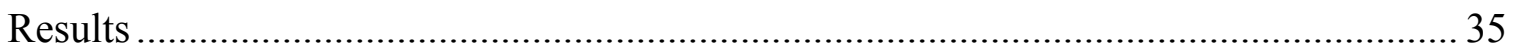




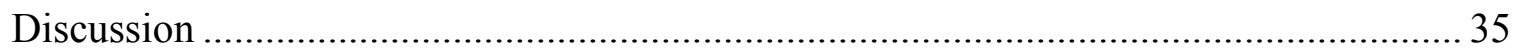

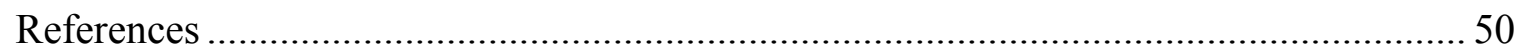

IV. DISCUSSION \& CONCLUSIONS ......................................................... 52

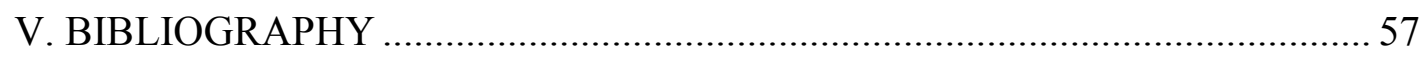




\section{LIST OF TABLES}

Table

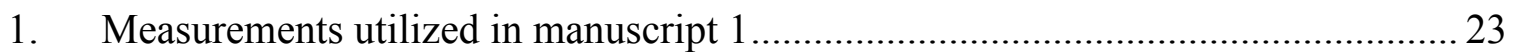

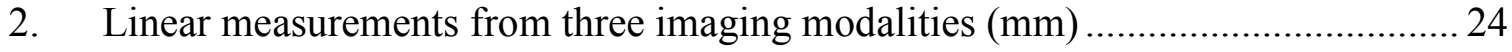

3. Angular measurements from three imaging modalities (degrees) .........................25

4a. ANOVA test of Actual Difference and Absolute Difference between image measurement and skull measurement of three mid-sagittal measurements for three imaging modalities

4b. Tukey Test of significant ANOVA factor (Image Modality for image-skull measurement Difference

4c. Tukey Test of significant ANOVA factor (Image Modality) for Absolute Value of image-skull measurement................................................................................... 26

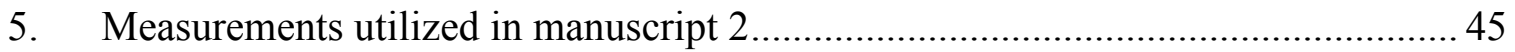

6. Differences between linear measurements $(\mathrm{mm})$ from three imaging modalities ... 46

7. P-values from the paired t-test for the linear measurements from three imaging modalities

8. Differences between angular measurements (degrees) from three imaging modalities

9. $\quad$ P-values from the paired t-test for the angular measurements from three imaging modalities 


\section{LIST OF FIGURES}

Figure $\quad$ Page

1. Orthogonal and perspective projections. Source side (S) and detector side (D) elements of a $3 \mathrm{D}$ object are not magnified in an orthogonal projection. In a perspective projection, $\mathrm{S}$ and $\mathrm{D}$ are magnified to differing degrees ..................................... 20

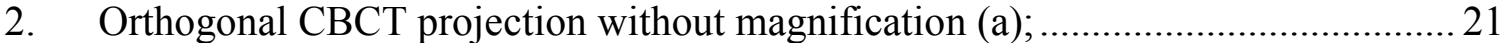

Perspective projection projection with $7.5 \%$ simulated magnification (b);............ 21

Conventional cephalogram of skull with inherent magnification of $7.5 \%$ (c) ........ 22 .

3. Dolphin 3D soft and hard tissue virtual model ............................................... 41

4. Orientation of the Dolphin 3D virtual model .................................................... 41

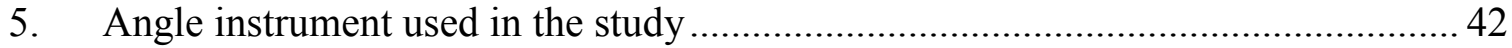

6a. Using angle instrument to record the natural head position in the conventional

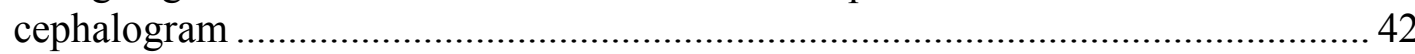

6b. Using angle instrument to simulate the natural head position in the CBCT synthesized

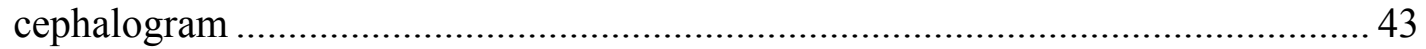

7. Orthogonal CBCT projection without magnification (a); .................................. 43

Perspective projection with 7.5\% simulated magnification (b); .......................... 44

Conventional cephalogram of skull with inherent magnification of $7.5 \%$ (c) ......... 44 


\section{LIST OF ABBREVIATIONS}

CBCT

2D

3D

CT

ANOVA

MANOVA

Cm

Dpi

DF

DICOM

Tukey HSD

SOD

SID

M

mm

SD

LFH

UFH

TFH

MnL

MxL

AN
Cone Beam Computed Tomography

Two-dimensional

Three-dimensional

Computed Tomography

Analysis of Variance

Multivariate analysis of variance

Centimeter

Dots per inch

Degrees of Freedom

Digital Imaging \& Communications in Medicine

Tukey Honestly significant difference

Source to object distance

Source to image receptor distance

Magnification

Millimeter

Standard deviation

Lower Face Height (ANS-Me)

Upper Face Height (N-ANS)

Total Anterior Face Height (N-Me)

Mandibular Unit length (Co-Gn)

Maxillary Unit Length (Co-ANS)

A to $\mathrm{N}$ with respect to true vertical 


\begin{tabular}{ll} 
BN & B to N with respect to true vertical \\
PgN & Pg to N with respect to true vertical \\
OJT & Overjet \\
SNA & Sella-Nasion-A \\
SNB & Sella-Nasion-B \\
FMA & Frankfort-Mandibular plane Angle \\
USN & Upper Incisor-Sella/Nasion \\
LMP & Lower Incisor-Mandibular Plane \\
ST & Soft tissue \\
LN & Lower lip to N with respect to true vertical \\
UN & Upper lip to N with respect to true vertical \\
PgN & Pg to N with respect to true vertical \\
ANS & Anterior Nasal Spine \\
Me & Menton \\
N & Point A \\
Co & Point B \\
Gn & Sella \\
Pg & Mandion \\
A & Condylion \\
G & Gnathion \\
Pogonion \\
Miff & Absolute Value Difference \\
\hline
\end{tabular}


Conv

CBCT-o

CBCT-p
Conventional cephalogram

CBCT synthesized orthogonal projection

CBCT synthesized perspective projection 


\section{INTRODUCTION}

\section{Background and Significance}

Cephalometric radiography is primarily used to describe the morphology and growth of the craniofacial skeleton. It is considered a valuable diagnostic aid in orthodontics for treatment planning and evaluating treatment results. Cephalometric analysis requires identifying specific landmarks and calculating various angular and linear dimensions. ${ }^{1}$ Lateral cephalometric radiographs, like all transmission radiographs, collapse the threedimensional (3D) structure in a two-dimensional (2D) plane. Two types of errors occur with this approach: errors of projection, and errors of identification.

Errors of projection occur due to imperfect enlargements caused by the unequal distances between the focus, the objects of interest (landmarks) within the skull and the image receptor. Magnification differences of $7-8 \%$ between the x-ray source side $\&$ image receptor side anatomy influence measurement \& cause either underestimation or overestimation of asymmetry. Imaging of structures that are not situated in the midsagittal plane and that appear bilaterally, produce a dual image on the radiograph. ${ }^{2}$ Deviations from the standard projection geometry and misalignment of the cephalostat together with rotation of the patients head in the cephalostat in any plane result in the errors of projection. ${ }^{3,4}$

Errors of identification occur due to observer variability in locating the various landmarks. Various factors like quality of radiographic image, precision of landmark definition, and reproducibility of landmark location as well as operator variability may allow only gross changes to be observed clearly, while subtle changes may be missed. ${ }^{5,6}$ 
Broadbent's introduction of the cephalostat underscored a philosophy of coordinating both the lateral and frontal head films to define the craniofacial form. But this is difficult to achieve and yields less accurate measurements than true anatomic values. The approach is reliant on identification of the same point on both radiographs and uses geometry to calculate the 3D position. This has the main limitation of inexact correspondence of landmark location on the 2 radiographs. Points not visible on both radiographs cannot be used. In addition; these images provide no information about anatomical relationships in the coronal plane. ${ }^{7}$

The introduction of digital imaging in dentistry generated many new research initiatives aimed at unlocking the diagnostic potential of radiography through image processing. Some of these initiatives have resulted in meaningful applications that have been shown to increase diagnostic utility. Some studies have compared measurements and superimpositions on analog radiographs with those made on scanned digital images and showed that the measurement differences between the original cephalograms and the digitized images are statistically significant but clinically acceptable. ${ }^{8-10}$ Digital cephalometric radiography can yield better or comparable performance in landmark identification than film, but digital images also suffer from the limitations of conventional cephalograms including magnification, distortion and superimposition of the anatomical structures.

Cephalometric superimposition and shape analysis are other ways of assessing orthodontic treatment outcomes. ${ }^{11}$ Different superimposition methods have different degrees of accuracy. Use of a less than accurate superimposition method may cause an inaccurate result leading to suboptimal surgical outcomes and treatment progress. ${ }^{12}$ In addition, the accuracy of superimposition is consistently associated with the examiner's experience, no 
matter what methods the examiner uses. ${ }^{13}$ Landmark identification remains the most popular method for diagnosis and treatment planning among orthodontists.

\section{Problem definition and Review of potential solutions}

The inability of conventional imaging modalities to provide consistently accurate results indicates the need for the development and study of alternative diagnostic imaging systems that carry the potential of improving the identification of anatomic landmarks and carrying out various linear and angular measurements. Precise anatomic data unobtainable by other means can be acquired from a 3D radiological image. ${ }^{14}$

Three-dimensional visualization of the craniofacial skeleton can be attained through computed tomography (CT). ${ }^{1516} \mathrm{CT}$ allows accurate assessment of the anatomic relationships in $3 \mathrm{D}$ and has lead to refinements in preoperative planning for many types of surgical procedures. ${ }^{17}$ Unfortunately, the effective dose of medical CT scans is much higher than with conventional radiography. ${ }^{18}$ This renders its use for routine cephalometric analysis and growth assessment unjustifiable. ${ }^{19} \mathrm{CT}$ is also relatively expensive and scanners are not easily accessible.

A new generation of compact CT scanners has been developed specifically for imaging the head and neck region. ${ }^{20}$ These scanners use a cone beam geometry which allows for better efficiency in x-ray photon utilization. ${ }^{21}$ The dose of from CBCT is relatively low. It can be less than the dose from a full mouth periapical series using D-speed film and round collimation and as much as 100 times less than the dose received from comparable medical CT imaging. ${ }^{22}$ CBCT scanners with a large field of view (9-12") allow three-dimensional reconstruction and visualization of the maxillofacial structures. In addition, various 
conventional views can be generated from the image volume, including panoramic, lateral and antero-posterior views.

The replacement of conventional cephalograms with CBCT for the assessment of craniofacial relationships has the potential to be a significant step forward in the diagnosis and treatment of selected orthodontic and surgical patients. CBCT volumes have the potential to overcome many of the limitations of conventional cephalometric imaging; however, 3D data present new challenges and need a different approach from traditional viewing of static images to make the most of the available information. Various techniques for the reconstruction of $\mathrm{CT}$ images have been used in diagnosis, treatment planning, and simulation. However, image superimposition for the assessment of changes with treatment poses many challenges. These challenges include registration and homology issues as well as the difficulty of landmark localization on anatomic surfaces. Three-dimensional landmark identification requires suitable operational definitions of the landmark location in each of the 3 planes of space. ${ }^{23}$

While the use of $3 \mathrm{D}$ analysis for diagnosis and treatment undergoes clinical validation, $2 \mathrm{D}$ image simulation tools may be used on $3 \mathrm{D}$ volumes and can help bridge the gap between 2D and 3D image types. ${ }^{24} \mathrm{CBCT}$ acquisitions can be made to simulate panoramic, lateral, and posteroanterior cephalometric radiographs so that they can be compared with preexisting image databases.

The Vision

Dentists have used cephalometry for more than 70 years, and orthodontists have grown accustomed to using lateral radiographs for examining patients and planning treatment. These methods are well established and have resulted in several large databases of 
normal and treated patient populations. ${ }^{1,} 25$ As dentistry moves from traditional 2D cephalometric analysis to new 3D techniques; it will often be useful to compare 2D with 3D data. Lateral cephalometric views can be reconstructed using orthogonal and perspective reconstructions, the latter matching the magnification and distortion of conventional cephalograms. The purpose of this study was to determine whether CBCT synthesized cephalograms provide the same measurement accuracy and precision as conventional cephalograms. 
MANUSCRIPT I

In vitro Comparison of Conventional and Cone Beam Synthesized

Cephalograms 


\section{Abstract}

OBJECTIVES: To compare cephalometric measurements from synthesized cone-beam CT (CBCT) lateral cephalograms using orthogonal and perspective projections with those from conventional cephalometric radiographs and dry skulls.

METHODS: Ten skulls were imaged using CBCT and conventional cephalometry. CBCT volume data were exported in DICOM format and imported in Dolphin 3D (pre release version). Orthogonal and perspective lateral cephalometric radiographs were created from 3D virtual models. Nine linear and five angular measurements were made in Dolphin at three different times. Three caliper measures of midsagittal landmarks were made directly on skulls. Perspective and conventional image measurements were corrected for known magnification. Reproducibility of measurements was assessed using MANOVA. Linear and angular measurements were compared between image modalities by measurement using a repeated measures MANOVA model. Differences and absolute value of differences between image measurements and skull measurements were assessed using ANOVA.

RESULTS: Measurements were not different between the imaging modalities $(\mathrm{p}>0.05)$, except for the mandibular unit length $(\mathrm{p}=0.01)$. Linear midsagittal measurements were significantly greater than skull measurements for perspective $\mathrm{CBCT}$ and significantly less than skull measurements for conventional images $(\mathrm{p}=0.003)$. Precision of orthogonal CBCT mid-sagittal linear measurements was significantly better than the other modalities $(\mathrm{p}=0.007)$. Orthogonal $\mathrm{CBCT}$ projections provide a more accurate midsagittal skull measurements than perspective $\mathrm{CBCT}$ or conventional cephalometric radiographs. 
CONCLUSIONS: CBCT can reproduce conventional cephalometric geometry with similar precision and accuracy. Orthogonal CBCT projections provided greater accuracy of measurement for midsagittal plane dimensions than perspective CBCT or conventional cephalometric images.

Key Words: Cephalometry, Tomography, X-Ray Computed 


\section{Introduction}

Cephalometric radiography is primarily used to describe the morphology and growth of the craniofacial skeleton. It is considered a valuable diagnostic aid in orthodontics for treatment planning and evaluating treatment results. Cephalometric analysis requires identifying specific landmarks and calculating various angular and linear dimensions. Lateral cephalometric radiographs, like all transmission radiographs, collapse the threedimensional (3D) structure in a two-dimensional (2D) plane. The resulting superimposition of anatomical structures complicates image interpretation and landmark identification. Moreover, structures closer to the $\mathrm{x}$ ray source appear more magnified than those closer to the detector, despite the usually large source-to-object distance. Deviations from the standard projection geometry and observer variability in landmark identification are considered major sources of error, which further complicate cephalometric analysis. ${ }^{1-3}$ In addition; cephalometric radiographs provide no information about anatomical relationships in the coronal plane. Antero-posterior views are of only limited assistance in this regard.

Three-dimensional visualization of the craniofacial skeleton can be attained through computed tomography (CT). CT allows accurate assessment of the anatomic relationships in 3D and has lead to refinements in preoperative planning for many types of surgical procedures. ${ }^{4,5}$ Unfortunately, the effective dose of medical CT scans is much higher than with conventional radiography ${ }^{6,7}$. This renders its use for routine cephalometric analysis and growth assessment unjustifiable. ${ }^{8} \mathrm{CT}$ is also relatively expensive and scanners are not easily accessible.

A new generation of compact CT scanners has been developed specifically for imaging the head and neck region. ${ }^{9}$. These scanners use a cone beam geometry, which 
allows for better efficiency in x-ray photon utilization. The dose of cone beam computed tomography $(\mathrm{CBCT})$ is relatively low. It can be less than the dose from a full mouth periapical series using D-speed film and round collimation and as much as 100 times less than the dose received from comparable medical CT imaging. ${ }^{10} \mathrm{CBCT}$ scanners with a large field of view (9-12") allow three-dimensional reconstruction and visualization of the maxillofacial structures. In addition, various conventional views can be generated from the image volume, including panoramic, lateral and antero-posterior views.

The replacement of conventional cephalograms with CBCT for the assessment of craniofacial relationships has the potential to be a significant step forward in the diagnosis and treatment of selected orthodontic and surgical patients. Since the standard population norms and the database is not available for the 3D CBCT volume, such patients for whom the $\mathrm{CBCT}$ data acquired for various above described reasons are subjected to further radiation exposure for the acquisition of the traditional lateral cephalograms and the panoramic radiographs for doing the traditional cephalometric tracings for assessing the growth and development of the craniofacial complex and to observe the outcome of the orthodontic treatment. This study was undertaken to emphasize the fact that traditional radiographic projections can be synthesized from this and the traditional cephalometric analysis can be done on these synthesized views with the similar precision and accuracy. Cephalometric superimpositions, shape analysis are the other ways of assessing the orthodontic treatment outcomes and different superimposition methods have different degrees of accuracy. The use of a less than accurate superimposition method may cause an inaccurate result. As a consequence, the inaccurate superimposition may distort the actual surgical outcomes and treatment progress. In addition, the accuracy of superimposition is 
consistently associated with the examiner's experience, no matter what methods the examiner uses and landmark identification still remain the most popular method among orthodontists and being used widely nationwide.

While much work is needed to demonstrate the added value of CBCT in these cases, it is not known whether data obtained from synthesized CBCT views can be compared with current population norms and existing databases obtained from conventional cephalograms. While synthesized views discard much of the $3 \mathrm{D}$ information embedded in CBCT image volumes, correspondence between $\mathrm{CBCT}$ and conventional radiography needs to be determined during this transition period.

The choices in synthesizing $2 \mathrm{D}$ views from an image volume are virtually unlimited. Lateral cephalometric views can be reconstructed using orthogonal and perspective reconstructions, the latter matching the magnification and distortion of conventional cephalograms. The purpose of this study was to determine whether CBCT synthesized cephalograms provide the same measurement accuracy and precision as conventional cephalograms. The specific aims were to test the null hypotheses that (1) cephalometric measurements are not different for conventional cephalometric radiographs and synthesized CBCT cephalograms using either perspective or orthogonal reconstruction algorithms and (2) measurements from CBCT synthesized images do not differ from actual skull measurements.

\section{Materials and Methods}

Ten dry skulls were used in this study. Prior to imaging, each mandible was stabilized against the opposing maxilla using orthodontic elastics. Conventional 
cephalograms were acquired by positioning the skulls in a cephalostat (Wehmer cephalostat, Addison, Illinois, U.S.A) and exposing them with a source-midsagittal plane distance of $152.4 \mathrm{~cm}$ (5 feet). A photostimulable phosphor plate was used as the detector and positioned $11.5 \mathrm{~cm}$ from the midsagittal plane. The plate was scanned and digitized at $300 \mathrm{dpi}$ (Digora PCT, Soredex, USA). CBCT volumes were acquired using a NewTom 3G (AFP Imaging, Elmsford, NY). Skulls were placed in a plastic bag and stabilized in a round plastic bucket with the Frankfort horizontal plane vertically oriented. The bucket was filled with water to simulate soft tissue attenuation and scattering of $\mathrm{x}$-rays. Table height was adjusted until the antero- posterior positioning laser was centered on the mid-ramus area of the jaw. A 12 inch field of view was selected to include the entire facial anatomy for cephalometric purposes. The "small field" and "high resolution" options were selected for primary image reconstruction. The secondary study data was generated with $0.5 \mathrm{~mm}$ axial slice thicknesses and isotropic voxels. The axial images were exported in DICOM format and imported in Dolphin 3D (pre-release version 1, Dolphin Imaging \& Management Systems, Chatsworth, CA). A 3D virtual model was created from the study. Using the axial view, the midsagittal plane of the model was oriented vertically. Using the coronal view, the transporionic line of the model was oriented horizontally. Using the sagittal view, the Frankfort plane of the model was oriented horizontally. Next, orthogonal and perspective radiographs were built from the reoriented model. An orthogonal projection is created by parallel rays . The perspective projection has a center of projection (focus) at a finite distance from the projection plane. The location of an object between the focus and the projection plane determines its size on the projection plane (Figure 1). The orthogonal radiographs were generated with $0 \%$ magnification (Figure 2a). Perspective radiographs were created using 
$7.5 \%$ magnification of the midsagittal plane (Figure $2 \mathrm{~b}$ ), and simulation of the geometry of the conventional cephalometric radiographs (Figure 2c). Dolphin imaging software (version 9.0.00.24) was used for cephalometric tracings of the $2 \mathrm{D}$ images. This study compared nine linear and five angular measurements based on sixteen landmarks (Table 1). For the identification of the landmarks, metallic points were used in the pilot study but those produced streaking artifacts in the synthesized cephalograms from the $\mathrm{CBCT}$ data and thus made their identification difficult. Therefore the attempts were made to interpret standard definitions of the anatomical landmarks in the conventional way and identify the landmarks accordingly. The measurements were selected to include both vertical and antero-posterior components of the craniofacial form. The landmarks on which these measurements were based represented both mid-sagittal and bilateral anatomical structures with different degrees of identification difficulty. Three linear mid-sagittal measurements were also obtained from the skulls using a digital caliper (Absolute Digimatic No. 500-172, Mitutoyo America Corp., Aurora, IL). The identification of mid-sagittal landmarks Nasion, Anterior Nasal Spine, and Menton were easily identified on the skull and these landmarks gave the three important measurements - upper face height, lower face height and the total face height. The other mid-sagittal landmarks like point A, point B, Pogonion (Pg) and Gnathion (Gn) are defined in a manner that their identification on the skull was not possible as the sharp edges seen in 2D projections are replaced by surfaces and curves in the skull

The measurements were made by a single operator $(\mathrm{VK})$ and repeated at three different time points with at least one week in between. The mean of the three repeat measurements was used for the final analysis. 
For the calculation of the magnification for conventional cephalograms, The source to the patient mid-sagittal distance in the Wehmer cephalostat used was 5 feet $(152.40 \mathrm{~cm})$ and the receptor to patient mid-sagittal distance used was $11.5 \mathrm{~cm}$ and by computing these values for calculating the magnification, value of $7.5 \%$ magnification was reached. The measurements for the perspective $\mathrm{CBCT}$ projections were adjusted for the $7.5 \%$ magnification. to simulate the conventional radiographs.

\section{Statistical Analysis:}

Repeated measurements were assessed by MANOVA. Averages of the 3 repeated measurements were also assessed by MANOVA testing the radiographic modalities as repeated measures for each measurement. Differences between midsagittal image measurements and comparable skull measurements were analyzed with ANOVA. Statistically significant model factors were assessed with Tukey HSD tests. The analysis was repeated using the absolute value of the image and skull measurement difference.

\section{Results}

Table 2 shows the mean values for nine linear measurements from the three imaging modalities. Differences between the modalities were not statistically significant, except for the mandibular unit length $(\mathrm{MnL})$. Table 3 shows the mean values for the five angular measurements from the three imaging modalities. None of the differences were statistically significant. Table 4(a, b and c) shows the mean differences and the mean absolute value of differences by midsagittal measurement and cephalometric modality. The ANOVA model demonstrated significant differences due to image modality for both difference and absolute

value of difference. The Tukey HSD test indicated that perspective CBCT and conventional cephalometric images differed from each other but that neither differed significantly from 
orthogonal CBCT. Absolute value of differences between perspective CBCT and conventional images were not significant; however, both were significantly different from orthogonal CBCT."

\section{Discussion:}

Lateral and frontal cephalograms together with facial photographs are currently the main diagnostic imaging modalities for the assessment of craniofacial hard and soft tissue morphology. The diagnostic information from these imaging modalities is considered valuable for treatment planning, prediction of growth and treatment results and evaluation of orthodontic and surgical outcomes. In lateral and frontal cephalograms, many structures overlap as complex three-dimensional (3-D) structures are projected onto a two-dimensional (2-D) plane. Moreover, the magnification and distortion inherent to conventional transmission radiography makes it difficult to accurately assess the patient's anatomy. ${ }^{11}$ While the potential advantages of three-dimensional CBCT imaging are evident, ${ }^{12,13}$ quantitative assessment of the 3-D facial form requires validation through comparison with traditional methods. Advances in CBCT imaging of the maxillofacial skeleton will be more readily accepted by clinicians if images can be synthesized that are similar to the ones they are familiar with and have used for several decades.

This study utilized skull measurements as the gold standard to assess the accuracy of three mid-sagittal image measurements. The conventional imaging modality under-estimates actual skull dimensions while the perspective CBCT over-estimates skull dimensions. Orthogonal CBCT provided measurements closest to the actual skull measurements and was significantly more precise than the other image modalities as assessed by the absolute differences. 
Theoretically, the magnification and distortion of perspective projection should not affect mid-sagittal measurements. This was not the case for the current study. One possible explanation is that the pattern of superimposing anatomy or noise differs in the conventional and perspective projection, which may have influenced feature recognition and measurement. The validity of this explanation is diminished by the fact that the distortion of perspective $\mathrm{CBCT}$ is intended to match that of conventional cephalometric images. Another possible explanation is that calculated magnification and actual magnification may differ in either or both Conventional and CBCT perspective image forming techniques. Calculated magnification is the one that calculated by computing the source to patient and patient to receptor distances in the formula for calculating magnification that is $\mathrm{M}=\mathrm{SOD} / \mathrm{SID}$ Actual magnification is the one determined by the reconstruction algorithm of the Dolphin 3D pre-release version used.

The CBCT perspective reconstruction is supposed to mimic conventional cephalograms in differential magnification of bilateral structures and magnification of the mid-sagittal plane which is user controlled to match specific source - midsagittal plane image receptor geometry. While the Dolphin 3D pre-release version simulates perspective distortion of bilateral structures, it does so while maintaining $100 \%$ magnification of the midsagittal plane and thus does not fully simulate a conventional cephalogram which will always exhibit a midsagittal magnification greater than $100 \%$ (7.5\% - 11\% typical). Another potential source for variation in perspective $\mathrm{CBCT}$ cephalograms is the reference, which the reconstruction algorithm uses for determining a midsagittal plane. If the center of the image volume is used, this may not coincide with the anatomic midsagittal plane. Because a 
cephalostat is not used in CBCT imaging, the skull position may be eccentric with respect to the volume. This potential source of measurement error was not explored in this study.

Although the skulls used in this study facilitated caliper measurement to establish ground truth, they provide an imperfect model of radiographic imaging of patients. The water bath used to simulate the soft tissue attenuation of $\mathrm{x}$-rays for CBCT does not equate in either quantity or distribution to the soft tissues seen in patients. Because of this, soft tissue landmark assessment could not be carried out. Due to the use of a cylindrical container, the volume of water in the medio-lateral dimension of the skull was disproportionately greater than the tissue volume found in patients. The additional medio-lateral attenuation of $\mathrm{x}$-rays may have reduced the contrast of skeletal landmarks of the CBCT volume.

The results of this study also show that of the fourteen cephalometric measurements, thirteen were not statistically different between the modalities. Ten of these measurements were located in the midsagittal plane and four were based on bilateral landmarks. Mediolateral displacement from the midsagittal plane introduces the possibility of imperfect superimposition in the lateral cephalometric image and the potential for increased variability of landmark identification. In conventional cephalometric imaging a head-holding device, consisting of an ear rod and nasal positioner, is used for lateral cephalometric radiographs to minimize the projection errors caused by head rotation around the vertical, transverse, and anteroposterior axes. Even when properly adjusted, the cephalostat cannot prevent slight translation or rotation of the patient's midsagittal plane. These variations in patient position may lead to variation in cephalometric measurements. Although 3D measurements of $\mathrm{CBCT}$ volumes are free from the influence of patient position during image acquisition ${ }^{14}$, the orientation of the secondary reconstruction of the volume directly impacts the projection of 
anatomy in synthesized 2D cephalometric views. Unlike errors in skull position seen in conventional cephalometric images due to faulty positioning of the cephalostat or faulty positioning of the patient within the cephalostat, orientation of the CT volume can be corrected by iterative adjustment and reassessment. The alignment of the transporionic axis using the 3D rendered volumes was sufficiently accurate to preclude differences in identification and measurement of the landmarks used in this study. The ability to reorient the volume means that cephalostat errors, common to conventional cephalometry, can be eliminated in equivalent $\mathrm{CBCT}$ projections.

Differential magnification of bilateral structures as a result of a projective imaging geometry also leads to imperfect superimposition of landmarks. This is true for conventional cephalometric projections and perspective reconstructions of CBCT volumes. Although measurement differences related to projective distortion of bilateral structures could be hypothesized, no significant difference for measurements involving Condylion, Gonion, Porion, or Orbitale were seen between Orthogonal CBCT, perspective CBCT, and conventional cephalometric images with the exception of the mandibular unit length. This is consistent with the observation of Lascala CA and coauthors that CBCT technique is reliable for use in a variety of clinical situations where linear measurements between anatomical sites are required. ${ }^{15}$

Locating 2D landmarks on complex curving structures is not a trivial problem. ${ }^{16,17}$. Location of 2D landmarks on the skull and the actual 3D CBCT model still poses a challenge. While viewing anatomy in 3 dimensions, it is evident that precise landmarks often do not exist. The sharp edges seen in 2D projections are replaced by surfaces and curves in the 3D rendering. For example, locating Porion $(\mathrm{P})$ on the CBCT synthesized 
projections was often a challenge. While ear rods used in conventional cephalograms indicate the location of the external auditory meatus, the anatomic porion is different from the external opening. The pioneering studies of Glat ${ }^{18}$ and Grayson ${ }^{19}$ described landmark locations as image features but emphasized that, as a set, they constitute a stringent abstraction from 3D image volumes. Assessment of landmark displacement is dependent on the coordinate system used when different cephalograms are superimposed. Various authors $20,21,22$ suggest advances towards studies of curves or surfaces in $3 \mathrm{D}$, referring to tens of thousands of 3D points to define geometry. Netherway and coauthors ${ }^{23}$ and Schaefer and coauthors ${ }^{24}$ used semi-landmarks on the surface to incorporate information about deficient direction in landmark definition into the analysis of 3D data. Richtsmeier J.T and coauthors ${ }^{25}$ evaluated the precision and repeatability of locating anatomic landmarks in three dimensions on CT slice.

While new methods of 3D assessment are under development, the results of this study suggest that synthesized cephalometric images from CBCT may be used to bridge the transition phase from $2 \mathrm{D}$ to $3 \mathrm{D}$ image analysis. Though there is stastically significant difference between the values when the mid-sagittal measurements are compared to skull but as those differences are very small these are not of much clinical relevance and thus both the projections can be used with the similar precision and accuracy as the conventional cephalograms. Based on our results it is possible to conclude that the CBCT technique is reliable for being applied at different clinical situations where the linear measurements between anatomical sites are required, such as pre-operative assessment for orthognathic surgeries, because the measurements made from the $\mathrm{CBCT}$ synthesized images are similar, 
although slightly smaller, than those of real distances between skull sites, so the need for additional conventional cephalograms is not necessary and thus patient exposure is reduced.

Further validation with patient data will be needed to confirm the reliability of CBCT synthesized cephalograms for comparison with pre-existing cephalometric databases.

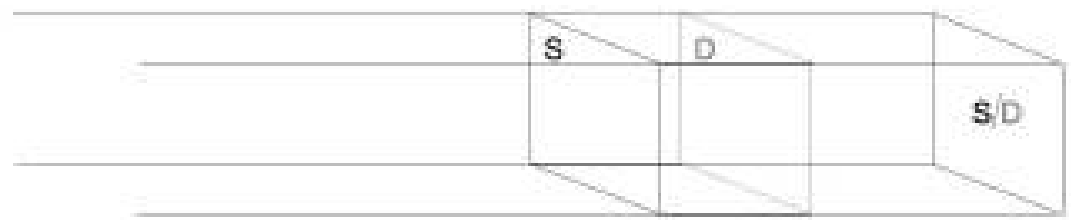

\section{Orthogonal Projection}

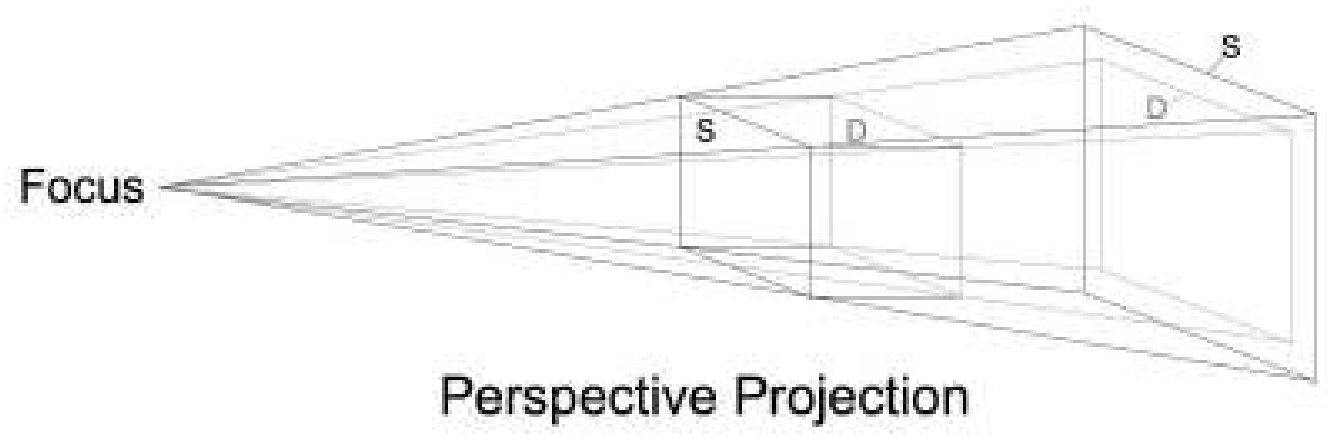

Figure 1: Orthogonal and perspective projections. Source side (S) and detector side (D) elements of a 3D object are not magnified in an orthogonal projection. In a perspective projection, S and D are magnified to differing degrees. 


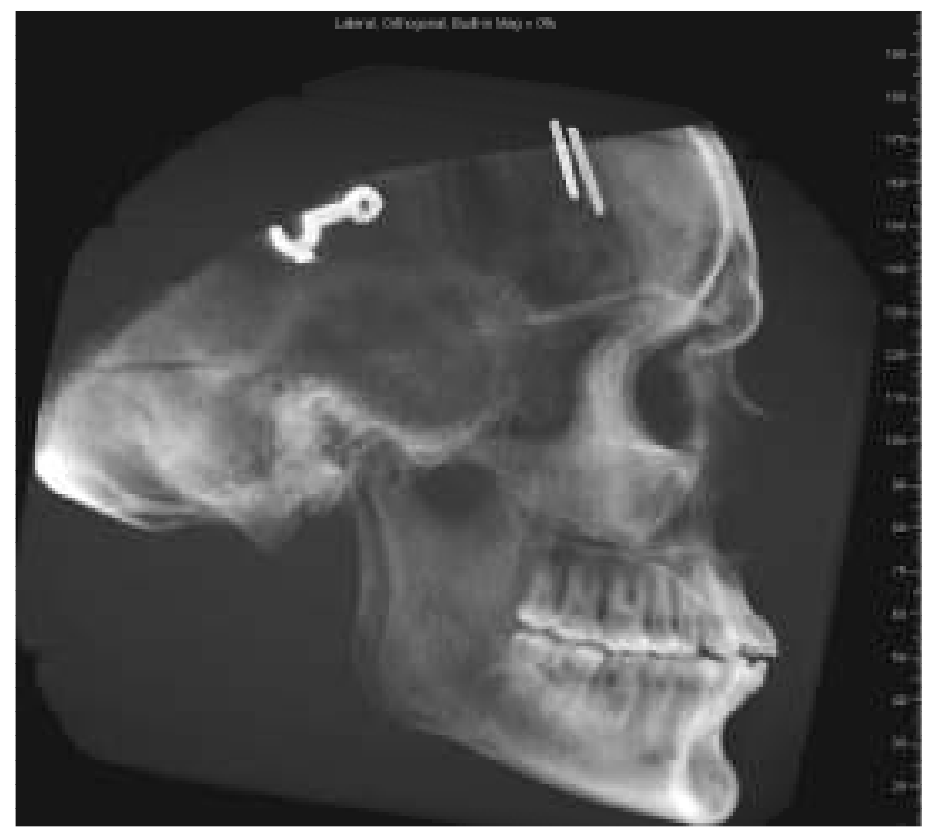

Figure 2a

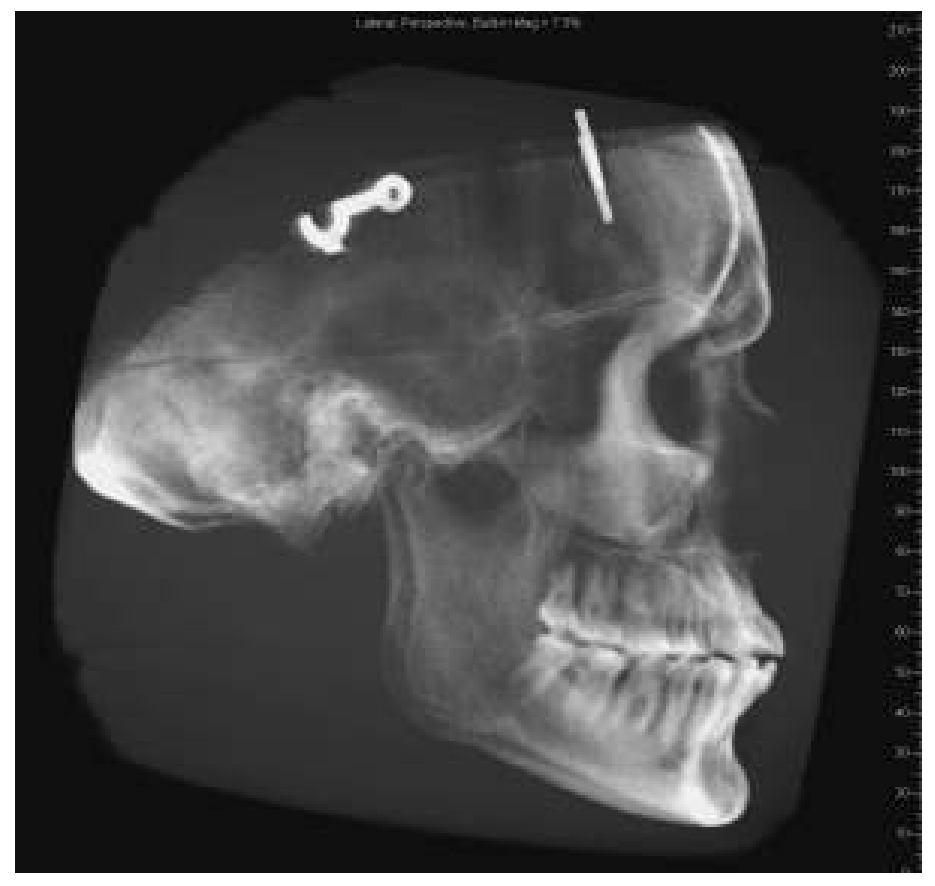

Figure $2 b$ 


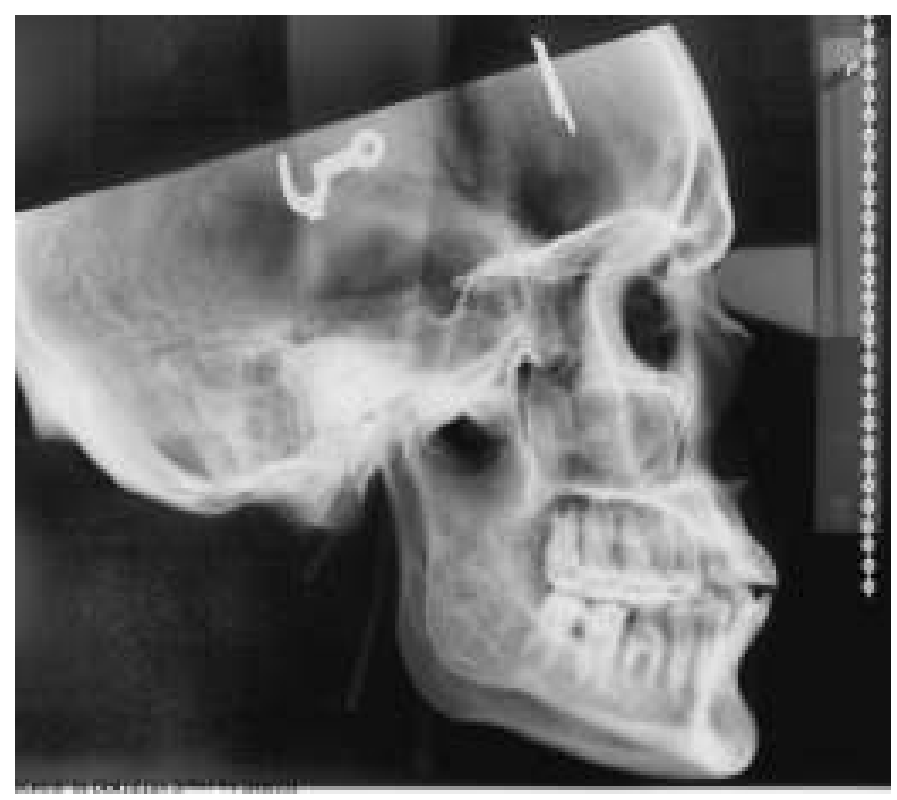

Figure 2c

Figure 2: Orthogonal CBCT projection without magnification (a); Perspective projection with $7.5 \%$ simulated magnification (b); Conventional cephalogram of skull with inherent magnification of $7.5 \%$. 


\begin{tabular}{|l|l|l|l|}
\hline \multicolumn{2}{|c|}{ Table 1: Measurements utilized in the study. } \\
\hline \multicolumn{2}{|c|}{ Linear Measurements } & \multicolumn{2}{c|}{ Angular Measurements } \\
\hline LFH: & Lower Face Height (ANS-Me) & SNA: & Sella-Nasion-A \\
\hline UFH: & Upper Face Height (N-ANS) & SNB: & Sella-Nasion-B \\
\hline TFH: & Total Anterior Face Height (N-Me) & FMA: & Frankfort-Mandibular plane Angle \\
\hline MnL: & Mandibular Unit length (Co-Gn) & USN: & Upper Incisor-Sella/Nasion \\
\hline MxL: & Maxillary Unit Length (Co-ANS) & LMP: & Lower Incisor-Mandibular Plane \\
\hline AN: & A to N with respect to true vertical & & \\
\hline BN: & B to N with respect to true vertical & & \\
\hline PgN: & $\begin{array}{l}\text { Pg to N with respect to true } \\
\text { vertical }\end{array}$ & & \\
\hline OJT: & Overjet & & \\
\hline $\begin{array}{l}\text { ANS: Anterior Nasal Spine; Me: Menton; N: Nasion; Co: Condylion; Gn: Gnathion; Pg: Pogonion; A: } \\
\text { point A; B: point B; S: Sella; Frankfort: Frankfort horizontal plane; MP: Mandibular Plane (Me-Go). }\end{array}$ \\
\hline
\end{tabular}


Table 2: Linear measurements from three imaging modalities (mm).

\begin{tabular}{|c|c|c|c|c|c|c|c|}
\hline & \multicolumn{2}{|c|}{ Conventional* } & \multicolumn{2}{|c|}{ CBCT-perspective $\uparrow$} & \multicolumn{2}{|c|}{ CBCT-orthogonal§ } & \multirow{2}{*}{$\begin{array}{c}\begin{array}{c}\text { MANOVA } \\
\text { Test }\end{array} \\
\text { P value }\end{array}$} \\
\hline & Mean & SD & Mean & SD & Mean & SD & \\
\hline LFH & 59.55 & 6.89 & 60.26 & 5.53 & 60.10 & 6.17 & 0.143 \\
\hline UFH & 48.29 & 5.00 & 48.02 & 4.45 & 49.92 & 4.82 & 0.435 \\
\hline TFH & 106.15 & 7.49 & 106.95 & 5.04 & 107.40 & 6.95 & 0.074 \\
\hline $\mathrm{MnL}$ & 107.99 & 6.84 & 110.73 & 7.81 & 109.99 & 7.67 & $0.010 \ddagger$ \\
\hline MxL & 81.30 & 2.85 & 82.29 & 5.19 & 82.84 & 4.46 & 0.317 \\
\hline AN & 2.12 & 3.00 & 2.14 & 3.93 & 2.42 & 2.92 & 0.900 \\
\hline $\mathrm{BN}$ & -4.69 & 5.25 & -3.35 & 5.86 & -4.37 & 4.61 & 0.598 \\
\hline PgN & -3.93 & 6.73 & -2.16 & 7.26 & -3.48 & 5.89 & 0.628 \\
\hline OJT & 4.45 & 2.15 & 4.67 & 2.54 & 5.36 & 2.82 & 0.361 \\
\hline \multicolumn{8}{|c|}{$\begin{array}{l}\text { * Conventional cephalograms adjusted for } 7.5 \% \text { magnification } \\
\text { † Synthesized cone-beam CT cephalograms with perspective projection adjusted for } 7.5 \% \text { magnification } \\
\text { \& Synthesized cone-beam CT cephalograms with orthogonal projection } \\
\$ \text { MANOVA for repeated measures statistically significant at } \mathrm{p}<0.05\end{array}$} \\
\hline
\end{tabular}




\begin{tabular}{|c|c|c|c|c|c|c|c|}
\hline & \multicolumn{2}{|c|}{ Conventional* } & \multicolumn{2}{|c|}{ CBCT-perspective $\uparrow$} & \multicolumn{2}{|c|}{ CBCT-orthogonal§ } & \multirow{2}{*}{$\begin{array}{c}\begin{array}{c}\text { MANOVA } \\
\text { Test }\end{array} \\
\text { P value }\end{array}$} \\
\hline & Mean & SD & Mean & SD & Mean & SD & \\
\hline SNA & 84.50 & 3.89 & 84.50 & 4.06 & 84.54 & 4.16 & 0.950 \\
\hline SNB & 79.02 & 3.92 & 79.91 & 4.09 & 78.96 & 4.06 & 0.764 \\
\hline FMA & 25.60 & 5.58 & 26.51 & 4.29 & 26.88 & 4.29 & 0.325 \\
\hline USN & 110.35 & 7.57 & 111.80 & 8.40 & 109.68 & 7.69 & 0.437 \\
\hline LMP & 102.22 & 5.73 & 101.94 & 4.75 & 100.97 & 6.12 & 0.415 \\
\hline
\end{tabular}

\begin{tabular}{|c|c|c|}
\hline \multicolumn{3}{|c|}{$\begin{array}{l}\text { Table 4a: ANOVA Test of Actual Difference and Absolute Difference } \\
\text { between image measurement and skull measurement of three mid- } \\
\text { sagittal Measurements§, for three Imaging Modalities } \dagger \text {. }\end{array}$} \\
\hline & \multicolumn{2}{|c|}{ P Values } \\
\hline Factor Tested & Difference & $\begin{array}{l}\text { Absolute value } \\
\text { of difference }\end{array}$ \\
\hline Measurement & 0.421 & 0.367 \\
\hline Image modality & $0.003 \dagger$ & $0.007+$ \\
\hline Image modality*Measurement & 0.191 & 0.582 \\
\hline
\end{tabular}

$\S$ Measurements: LFH, UFH, TFH

$\dagger$ Image modalities: Conventional, CBCT-perspective, CBCT-orthogonal

* Interaction term

† Statistically significant at $\mathrm{p}<0.05$ 


\begin{tabular}{|c|c|c|c|c|c|c|}
\hline \multicolumn{7}{|c|}{$\begin{array}{l}\text { Table 4b: Tukey Test of significant ANOVA factor (Image Modality) for image - skull } \\
\text { measurement Difference }\end{array}$} \\
\hline \multicolumn{7}{|c|}{ Difference (Image measurement - Skull Measurement) } \\
\hline & & LFH & UFH & TFH & Combined & $\begin{array}{l}\text { Tukey } \\
\text { HSD* }\end{array}$ \\
\hline CBCT-perspective & $\begin{array}{l}\text { Diff } \\
(\mathrm{SD})\end{array}$ & $\begin{array}{l}-1.29 \\
(2.06)\end{array}$ & $\begin{array}{c}-0.16 \\
(1.04)\end{array}$ & $\begin{array}{l}-1.63 \\
(2.27)\end{array}$ & 1.013 & A \\
\hline CBCT-orthogonal & $\begin{array}{l}\text { Diff } \\
\text { (SD) }\end{array}$ & $\begin{array}{l}-0.22 \\
(0.36)\end{array}$ & $\begin{array}{c}-0.32 \\
(0.38)\end{array}$ & $\begin{array}{l}-0.33 \\
(0.55)\end{array}$ & 0.286 & $\mathrm{AB}$ \\
\hline Conventional & $\begin{array}{l}\text { Diff } \\
\text { (SD) }\end{array}$ & $\begin{array}{c}0.34 \\
(1.29)\end{array}$ & $\begin{array}{c}0.31 \\
(1.54)\end{array}$ & $\begin{array}{c}0.92 \\
(1.61)\end{array}$ & -0.527 & B \\
\hline
\end{tabular}

*Tukey HSD-Levels not designated by the same letter is statistically significant

Table 4c: Tukey Test of significant ANOVA factor (Image Modality) for Absolute Value of image - skull measurement Difference

Absolute Value of Difference (|Image measurement - Skull Measurement|)

\begin{tabular}{|c|c|c|c|c|c|c|}
\hline & & LFH & UFH & $\mathrm{TFH}$ & Combined & $\begin{array}{l}\text { Tukey } \\
\text { HSD* }\end{array}$ \\
\hline CBCT-perspective & $\begin{array}{c}\text { Abs Val } \\
\text { Diff (SD) }\end{array}$ & $\begin{array}{c}1.36 \\
(2.01)\end{array}$ & $\begin{array}{c}0.82 \\
(0.59)\end{array}$ & $\begin{array}{c}1.63 \\
(2.27)\end{array}$ & 1.264 & A \\
\hline Conventional & $\begin{array}{c}\text { Abs Val } \\
\text { Diff (SD) }\end{array}$ & $\begin{array}{c}0.81 \\
(1.04)\end{array}$ & $\begin{array}{c}1.26 \\
(0.85) \\
\end{array}$ & $\begin{array}{c}1.48 \\
(1.05) \\
\end{array}$ & 1.183 & A \\
\hline CBCT-orthogonal & $\begin{array}{c}\text { Abs Val } \\
\text { Diff (SD) }\end{array}$ & $\begin{array}{c}0.34 \\
(0.23)\end{array}$ & $\begin{array}{c}0.39 \\
(0.29)\end{array}$ & $\begin{array}{c}0.38 \\
(0.51)\end{array}$ & 0.372 & $\mathrm{~B}$ \\
\hline
\end{tabular}

* Tukey HSD-Levels not designated by the same letter is statistically significant 


\section{REFERENCES}

1. Ahlqvist J, Eliasson S, Welander U. The effect of projection errors on cephalometric length measurements. Eur J Orthod 1986; 8:141-148

2. Chen YJ, Chen SK, Chang HF, Chen KC. Comparison of landmark identification in traditional versus computer-aided digital cephalometry. Angle Orthod 2000; 70:387-392

3. Chen YJ, Chen SK, Huang HW, Yao CC, Chang HF. Reliability of landmark identification in cephalometric radiography acquired by a storage phosphor imaging system. Dentomaxillofac Radiol 2004; 33:301-306

4. Mah J, Hatcher D. Current status and future needs in craniofacial imaging. Orthod Craniofac Res 2003; 6 Suppl 1:10-6; discussion 179-82

5. Cavalcanti MG, Rocha SS, Vannier MW. Craniofacial measurements based on 3D-CT volume rendering: implications for clinical applications. Dentomaxillofac Radiol 2004; $33: 170-176$

6. Ekestubbe A, Thilander A, Grondahl K, Grondahl HG. Absorbed doses from computed tomography for dental implant surgery: comparison with conventional tomography. Dentomaxillofac Radiol 1993; 22:13-17

7. Scaf G, Lurie AG, Mosier KM, Kantor ML, Ramsby GR, Freedman ML. Dosimetry and cost of imaging osseointegrated implants with film-based and computed tomography. Oral Surg Oral Med Oral Pathol Oral Radiol Endod 1997; 83:41-48

8. Hilgers ML, Scarfe WC, Scheetz JP, Farman AG. Accuracy of linear temporomandibular joint measurements with cone beam computed tomography and digital cephalometric radiography. Am J Orthod Dentofacial Orthop 2005; 128:803-811

9. Sukovic P. Cone beam computed tomography in craniofacial imaging. Orthod Craniofac Res 2003; 6 Suppl 1:31-6; discussion 179-82

10. Ludlow JB, Davies-Ludlow LE, Brooks SL. Dosimetry of two extraoral direct digital imaging devices: NewTom cone beam CT and Orthophos Plus DS panoramic unit. Dentomaxillofac Radiol 2003; 32:229-234

11. Grayson B, Cutting C, Bookstein FL, Kim H, McCarthy JG. The three-dimensional cephalogram: theory, technique, and clinical application. Am J Orthod Dentofacial Orthop 1988; 94:327-337

12. Hassfeld S, Muhling J. Computer assisted oral and maxillofacial surgery--a review and an assessment of technology. Int J Oral Maxillofac Surg 2001; 30:2-13 
13. Nakasima A, Terajima M, Mori N, et al. Three-dimensional computer-generated head model reconstructed from cephalograms, facial photographs, and dental cast models. $\mathrm{Am}$ J Orthod Dentofacial Orthop 2005; 127:282-292

14. Laster WS, Ludlow JB, Bailey LJ, Hershey HG. Accuracy of measurements of mandibular anatomy and prediction of asymmetry in panoramic radiographic images. Dentomaxillofac Radiol 2005; 34:343-349

15. Lascala CA, Panella J, Marques MM. Analysis of the accuracy of linear measurements obtained by cone beam computed tomography (CBCT-NewTom). Dentomaxillofac Radiol 2004; 33:291-294

16. Baumrind S, Moffitt F. Mapping the skull in 3-d. J Calif Dent Assoc 1972; 48:22-31

17. Harrell WE,Jr, Hatcher DC, Bolt RL. In search of anatomic truth: 3-dimensional digital modeling and the future of orthodontics. Am J Orthod Dentofacial Orthop 2002; $122: 325-330$

18. Glat PM, Freund RM, Spector JA, et al. A classification of plagiocephaly utilizing a three-dimensional computer analysis of cranial base landmarks. Ann Plast Surg 1996; $36: 469-474$

19. Grayson B, Cutting C, Bookstein FL, Kim H, McCarthy JG. The three-dimensional cephalogram: theory, technique, and clinical application. Am J Orthod Dentofacial Orthop 1988; 94:327-337

20. Mafart B, Guipert G, de Lumley MA, Subsol G. Three-dimensional computer imaging of hominid fossils: a new step in human evolution studies. Can Assoc Radiol J 2004; 55:264-270

21. Kragskov J, Bosch C, Gyldensted C, Sindet-Pedersen S. Comparison of the reliability of craniofacial anatomic landmarks based on cephalometric radiographs and threedimensional CT scans. Cleft Palate Craniofac J 1997; 34:111-116

22. Lagravere MO, Major PW. Proposed reference point for 3-dimensional cephalometric analysis with cone-beam computerized tomography. Am J Orthod Dentofacial Orthop 2005; $128: 657-660$

23. Netherway DJ, Abbott AH, Gulamhuseinwala N, et al. Three-Dimensional Computed Tomography Cephalometry of Plagiocephaly: Asymmetry and Shape Analysis. Cleft Palate Craniofac J 2006; 43:201-210

24. Schaefer K, Lauc T, Mitteroecker P, Gunz P, Bookstein FL. Dental arch asymmetry in an isolated Adriatic community. Am J Phys Anthropol 2006; 129:132-142

25. Richtsmeier JT, Paik CH, Elfert PC, Cole TM,3rd, Dahlman HR. Precision, repeatability, and validation of the localization of cranial landmarks using computed tomography scans. Cleft Palate Craniofac J 1995; 32:217-227 


\title{
MANUSCRIPT II
}

In Vivo Comparison of Conventional and Cone Beam Synthesized

\author{
Cephalograms
}




\begin{abstract}
OBJECTIVES: To compare measurements from synthesized cone-beam computed tomography (CBCT) lateral cephalograms using orthogonal and perspective projections with those from conventional cephalometric radiographs of patients.

METHODS: Thirty one patients from the UNC Dentofacial Deformities Program were imaged using $\mathrm{CBCT}$ and conventional cephalometry. CBCT volume data were exported in DICOM format and imported in Dolphin 3D. Orthogonal and perspective lateral cephalometric radiographs were created from three dimensional (3D) virtual models. Twelve linear and five angular measurements were made in Dolphin on synthesized and conventional cephalograms in a randomized fashion. Perspective and conventional image measurements were corrected for known magnification. Linear and angular measurements were compared between image modalities using paired t-tests. Bonferroni correction for multiple comparisons lowered the $\alpha$-level to 0.003 .

RESULTS: Measurements were not different between the imaging modalities ( $p>0.003$ ), except for the Frankfort-mandibular plane angle $(\mathrm{p}=0.0001)$. Linear measurements, whether based on soft or hard tissue landmarks, were not statistically different.

CONCLUSIONS: Measurements from in vivo CBCT synthesized cephalograms are similar to those based on conventional radiographic images. Thus, additional conventional imaging may be avoided when CBCT scans are acquired for orthodontic diagnosis.

Key Words: Cephalometry, Tomography, X-Ray Computed
\end{abstract}




\section{Introduction:}

Cephalometry is an essential clinical and research tool in orthodontics. It continues to be the most utilized diagnostic test to obtain absolute and relative measures of the craniofacial skeleton and has been relied upon for decades. Lateral cephalograms are twodimensional (2D) radiographs that are used to depict three dimensional (3D) structures. Consequently, cephalograms have inherent limitations as a result of distortion and differential magnification of the craniofacial complex. This may lead to errors of identification and reduced measurement accuracy. ${ }^{1-3}$

Three-dimensional imaging techniques are becoming increasingly popular and have opened new possibilities for orthodontic diagnosis, treatment assessment, and follow-up. ${ }^{4}$ Despite the usefulness and versatility of computed tomography (CT), the high cost of the examination, limited access to scanners, and relatively high radiation exposure make this modality unsuitable for orthodontic purposes. ${ }^{5}$ The recent introduction of maxillofacial cone beam computed tomography $(\mathrm{CBCT})$ has made 3D imaging more readily available for use in dental applications. The major advantages of CBCT over conventional CT include low radiation dose, lower cost, potentially better access, and high spatial resolution. ${ }^{6-8}$ While an increasing number of applications are being described in the literature; the modality is relatively new and requires systematic assessment to confirm its clinical usefulness. CBCT volumes have the potential to overcome many of the limitations of conventional cephalometric imaging. However, 3D data present new challenges and need a different approach from traditional viewing of static images to make the most of the available information. Various techniques for the reconstruction of CT images have been used in diagnosis, treatment planning, and simulation. Image volume superimposition for the 
assessment of changes is interesting but poses many challenges. These challenges include registration and homology issues as well as the difficulty of landmark localization on anatomic surfaces. Three-dimensional landmark identification requires suitable operational definitions of the landmark location in each of the 3 planes of space. ${ }^{9}$ While the use of 3D analysis for diagnosis and treatment undergoes clinical validation; 2D image simulation tools may be used on 3D volumes and can help bridge the gap between $2 \mathrm{D}$ and $3 \mathrm{D}$ image types. $\mathrm{CBCT}$ image data can be used to simulate panoramic, lateral, and posteroanterior cephalometric radiographs so that they can be compared with preexisting image databases. ${ }^{10}$ Dentists have used cephalometry for more than 70 years and orthodontists have grown accustomed to using lateral radiographs for examining patients and planning treatment. As dentistry moves from traditional 2D cephalometric analysis to new 3D techniques, it is useful to compare 2D with 3D data. If cephalometric measurements from $\mathrm{CBCT}$ data are comparable to those from traditional $2 \mathrm{D}$ views, patients may not need to be subjected to further radiation exposure for the acquisition of traditional lateral cephalograms and panoramic radiographs.

Lateral cephalometric views can be reconstructed from CBCT volumes using orthogonal and perspective reconstructions, the latter matching the magnification and distortion of conventional cephalograms. A previous study suggested that measurements from CBCT synthesized cephalograms are similar to those from conventional cephalograms in vitro. ${ }^{11}$ The purpose of this study was to determine whether CBCT synthesized cephalograms provide the same measurement accuracy and precision as conventional cephalograms when applied to patients. The specific aims were to test the null hypotheses that cephalometric measurements are similar for conventional cephalometric radiographs and 
synthesized CBCT cephalograms using either perspective or orthogonal reconstruction algorithms.

\section{Material and Methods:}

Thirty-one patients (13 male, 18 female; $21.6 \pm 7.9$ years) treated in the Dentofacial Deformities Program at the University of North Carolina School of Dentistry were recruited for this study. Informed consent was obtained from all subjects and the experimental protocols were approved by the Institutional Review Board.

Conventional cephalograms were acquired by positioning the patients in a cephalostat in natural head position (Wehmer cephalostat, Addison, Illinois, U.S.A). The sourcemidsagittal plane distance was $152.4 \mathrm{~cm}$ (5 feet). A photostimulable phosphor plate was used as the detector and positioned $11.5 \mathrm{~cm}$ from the midsagittal plane. The plate was scanned at 300 dpi (Digora PCT, Soredex, USA).

Presurgical CBCT scans were made one week before orthognathic surgery with the NewTom 3G (AFP Imaging, Elmsford, NY). The imaging protocol utilized a 12 inch field of view to include the entire facial anatomy for cephalometric purposes. The "large field" and "high resolution" options were selected for primary image reconstruction. The secondary study data were generated such that the axial slice thickness was $0.5 \mathrm{~mm}$ and the voxels isotropic. The axial images were exported in DICOM format and imported in Dolphin 3D (pre-release version 1, Dolphin Imaging \& Management Systems, Chatsworth, CA). A 3D virtual model was created from the study (Fig.3). Using the axial view, the midsagittal plane of the model was oriented vertically. Using the coronal view, the transporionic line of the 
model was oriented horizontally. Using the sagittal view, the Frankfort horizontal plane of the model was oriented horizontally (Fig. 4).

An "Original True Angle" angle measuring instrument (Quint Measuring Systems, San Ramon, CA) was used to simulate the conventional cephalogram orientation (Fig. 5). One scale of the instrument was placed parallel to the monitor screen and the other scale was placed touching the most prominent points of the patient mid frontal bone and the mid symphyseal region of the mandible in the conventional cephalogram. Both the scales were affixed at that point and that angle was reproduced on the right sagittal side of the $3 \mathrm{D}$ virtual model in Dolphin 3D (Fig. 6a and Fig. 6b).

Next, orthogonal and perspective radiographs were built from the reoriented model. The orthogonal radiographs (Fig.7a) were generated with $0 \%$ magnification. An orthogonal projection is created by parallel rays. Perspective radiographs (Fig.7b) were created simulating the geometry of the conventional cephalometric radiographs (Fig.7c) with the midsagittal plane of the patient at 5 feet.

Dolphin imaging software (version 9.0.00.24) was used for cephalometric tracings of the 2D images. This study compared twelve linear and five angular measurements based on nineteen soft and hard tissue landmarks (Table 5). The measurements were selected to include both vertical and antero-posterior components of the craniofacial form. The landmarks on which these measurements were based represented both mid-sagittal and bilateral anatomical structures with different degrees of identification difficulty. The measurements were made by a single operator (VK) in a randomized fashion. The measurements for the perspective $\mathrm{CBCT}$ projections and the conventional cephalograms were adjusted for the $7.5 \%$ midsagittal magnification. 


\section{Statistical Analysis:}

The paired t-test was used to test the three radiographic modalities for each measurement. Bonferroni correction for multiple comparisons was applied that lowered the alpha level for a two-tailed t-test to 0.003 .

\section{Results:}

Table 6 shows the mean difference values for twelve linear measurements from the paired comparisons of the three imaging modalities. None of the differences were statistically significant (Table 7). Table 8 shows the mean difference values for the five angular measurements from the three-paired comparisons of the imaging modalities. Differences between the modalities were not statistically significant, except for Frankfort-Mandibular plane Angle (FMA) when the adjusted conventional cephalograms were compared with the CBCT synthesized orthogonal and the perspective projections, (Table 9).

\section{Discussion:}

Cephalometry is a valuable tool for diagnosis of skeletal imbalance, growth assessment, response to treatment, and long term stability following orthodontic treatment. Cephalometric evaluation of patients with orthodontic needs has traditionally been performed by lateral and frontal cephalograms. These methods are well established and have resulted in several large databases of normal and treated patient populations. The cephalometric analysis is accomplished by measuring lengths and angles based on various cranio-facial hard and soft tissue landmarks. Since standard population norms are not available for 3D CBCT volumes, patients for whom CBCT data are acquired may be subjected to further radiation exposure for 
the acquisition of traditional lateral cephalograms and panoramic radiographs. Unlike conventional cephalograms, computed tomography has no inherent distortion of anatomic structures. As a result, more accurate measurements have been reported for planar 2D CT images. ${ }^{12}$ The current study was undertaken to emphasize the fact that traditional radiographic projections can be synthesized from CBCT volumes and traditional cephalometric analysis can be done on these synthesized views with similar precision and accuracy. While much work is needed to demonstrate the added value of CBCT in standard orthodontic cases, it is not known whether data obtained from synthesized CBCT views can be compared with current population norms and existing databases obtained from conventional cephalograms. Because synthesized views discard much of the 3D information embedded in $\mathrm{CBCT}$ image volumes, the demonstration of correspondence between $\mathrm{CBCT}$ and conventional radiography would be useful during this transition period.

The results of this study showed that the linear measurements of the three imaging modalities were not statistically different. All the angular measurements were also not stastically significant except for one angular measurement that is Frankfort mandibular plane angle (FMA). Every system has various sources of noise. In this study, only projection as the source of noise was explored, but other sources like landmark definition, observer variability in landmark identification and the ability to digitize the landmarks were not investigated. The cephalometric literature reveals that the landmarks like condylion, porion and gonion, which are used to define the Frankfort horizontal plane and the mandibular plane have, greater margins of error. ${ }^{13,14}$ The literature shows that superimposition of the bilateral middle ear and other temporal fossa structures make the identification of anatomical porion difficult and thus influenced the measurement of FMA angle. ${ }^{15}$ Landmarks like gonion and condylion are 
located on curved surfaces and are thus difficult to identify accurately. ${ }^{16}$ These various sources of noise might have influenced some of the measurements.

Although FMA is defined by cephalometric landmarks menton, gonion, porion, and orbirtale, it appears unlikely that identification of menton and gonion are responsible for the significant difference between images seen in this study. This is because LMP, another angular measurement dependent on the identification of menton and gonion, was not significantly different for the different projections. Mean angular differences between techniques were less than $1.1^{\circ}$ for LMP while mean differences rose to $4.1^{\circ}$ for Conventional - Orthogonal CBCT comparisons and $4.4^{\circ}$ for Perspective CBCT -Conventional comparisons of FMA. Because orbitale is not usually considered a difficult-to-identify landmark, the apparent source of variability appears to be the identification of porion. In instances where porion could not be identified in conventional images, ear rods were used as a surrogate landmark. As the location of the ear rods and the osseous periphery of the ear canal do not always coincide, this may have been a source of error. While cephalostats are not used in CBCT imaging, it would be possible to place ear plugs in the patient's ear canals to simulate the appearance of cephalostat ear rods.

Perspective imaging geometry leads to imperfect superimposition of bilateral structures. This is true for conventional cephalometric projections and perspective reconstructions of $\mathrm{CBCT}$ volumes. Although measurement differences related to projective distortion of bilateral structures could be hypothesized, this study showed no significant difference for measurements involving Condylion and Gonion between orthogonal CBCT, perspective $\mathrm{CBCT}$, and conventional cephalometric images. This is consistent with the 
observation of Lascala $\mathrm{CA}$ and coauthors that $\mathrm{CBCT}$ technique is reliable for use in a variety of clinical situations where linear measurements between anatomical sites are required. ${ }^{17}$ The CBCT perspective reconstruction is supposed to mimic conventional cephalograms in differential magnification of bilateral structures and magnification of the mid-sagittal plane. This is user-controlled to match specific source-midsagittal plane-image receptor geometry. While the Dolphin 3D pre-release version simulates perspective distortion of bilateral structures, it does so while maintaining $100 \%$ magnification of the midsagittal plane. Thus, it does not fully simulate a conventional cephalogram, which will always exhibit a midsagittal magnification greater than $100 \%(7.5 \%-11 \%$ typical $)$. Another potential source of variation in perspective $\mathrm{CBCT}$ cephalograms is the reference used to determine the midsagittal plane for the reconstruction algorithm. The center of the image volume may not coincide with the anatomical midsagittal plane. Because a cephalostat is not used in CBCT imaging, the patient position may be eccentric with respect to the volume. Patient positioning is considered critical for cephalometric analysis. ${ }^{18}$ The conventional cephalograms produced in the UNC School of Dentistry are taken in natural head position using a cephalostat consisting of ear rods and a nasal positioner. Natural head position is the position taken by the head when a subject is looking at a distant point at eye level. ${ }^{19}$ The purpose of the cephalostat is to minimize projection errors caused by head rotation around the vertical, transverse, and anteroposterior axes. The problem usually encountered while taking the conventional cephalogram is that even when the cephalostat is properly adjusted, it cannot prevent slight translation or rotation of the patient's midsagittal plane. These variations in patient position may lead to variation in cephalometric measurements. ${ }^{18,20}$ Although 3D measurements of $\mathrm{CBCT}$ volumes are free from the influence of patient position during image acquisition; the 
orientation of the secondary reconstruction of the volume directly impacts the projection of anatomy in synthesized 2D cephalometric views. In order to remove potential sources of measurement error in the synthesized views, the orientation of the CT volume was corrected by iterative adjustment and reassessment and the natural head position was simulated by using the angle instrument. The alignment of the transporionic axis using the 3D rendered volumes was sufficiently accurate to preclude differences in identification and measurement of the landmarks used in this study. The ability to reorient the volume means that cephalostat errors, common to conventional cephalometry, can be eliminated in equivalent CBCT projections.

Natural head position has been proposed as a reference position for assessing craniofacial morphology, and it has been advocated as a better alternative than intracranial reference lines because of its alleged lower variability. ${ }^{21}$ Ferrario et al. observed that the soft tissue Frankfort plane (tragus-orbitale) was not parallel to the hard tissue Frankfort plane (porion-orbitale), the two showing a deviation of $6^{\circ}$ on average. ${ }^{22}$ Lundström and Lundström used tracings of the soft tissue outlines from cephalometric radiographs and measured the inclination of the hard tissue Frankfort plane when the tracings were positioned at the natural head position by two trained assessors. They found a slightly upward inclination of $1-2^{\circ} .^{23}$ Although natural head position can be reproduced in CBCT volumes; it is debatable whether natural head position can be produced during actual positioning of the patient during CBCT imaging. This problem is obvious for an imaging protocol where the patient must be supine during image acquisition. Less obvious, but still problematic is the situation where a seated or standing patient must be stabilized in a head holder to reduce the risk of motion artifacts. Typically, CBCT unit restraints and guides are not designed to promote natural head 
position. Alternative approaches for orienting patients' volumes will be required in the future. Use of defined anatomic references, such as the Frankfort plane, is an obvious solution for standardization of images. Alternately, CT volumes may be registered with either 2D or 3D photographic images of the patient in natural head position. This type of registration is now routinely done with $\mathrm{CT}$ and $\mathrm{MR}$ volumes.

While new methods of 3D assessment are under development, the results of this study suggest that synthesized cephalometric images from CBCT may be used to bridge the transition from 2D to 3D image analysis. The statistically significant difference between the values of one of the angle measurements of synthesized projections compared to conventional lateral views requires further investigation. Although these differences were relatively small, they could be clinically relevant. In general, the results of this study suggest that both types of synthesized projections can be used with a precision and accuracy similar to conventional cephalograms and that cephalometric view generated from $\mathrm{CBCT}$ volumes may be used in place of conventional cephalometric images. If CBCT volumes are acquired, additional conventional cephalograms should be avoided to reduce $\mathrm{x}$-ray exposure and examination expense. 


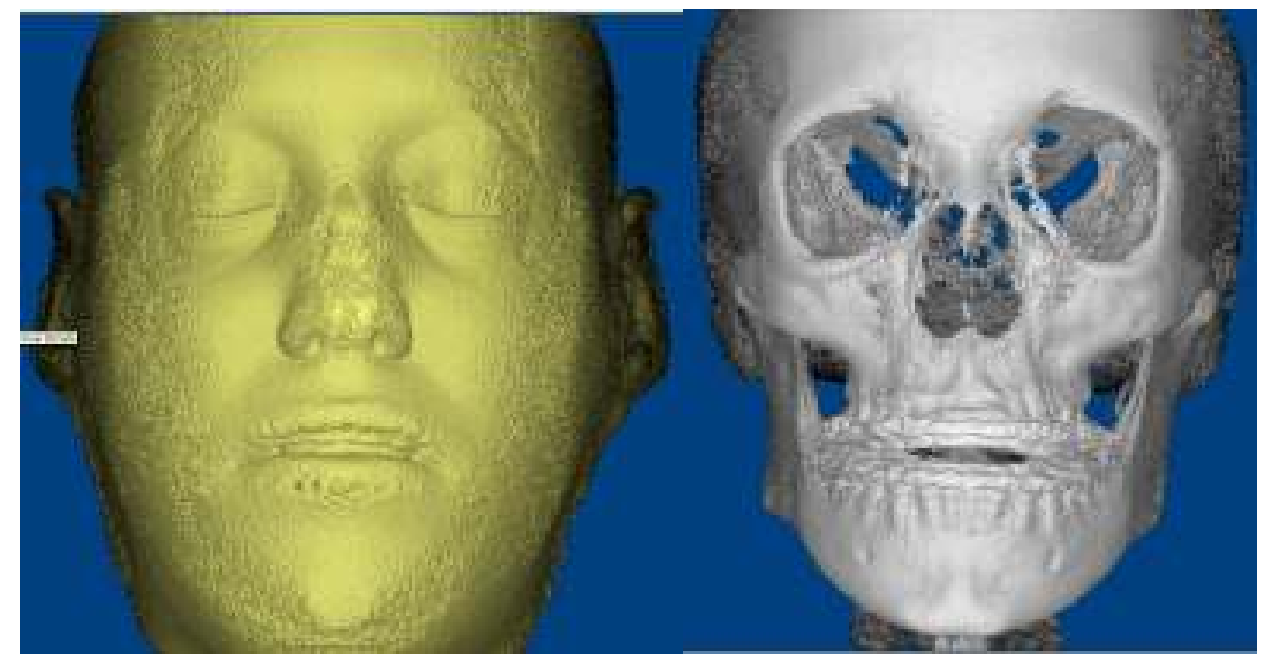

Figure3: Dolphin 3D soft and hard tissue virtual model

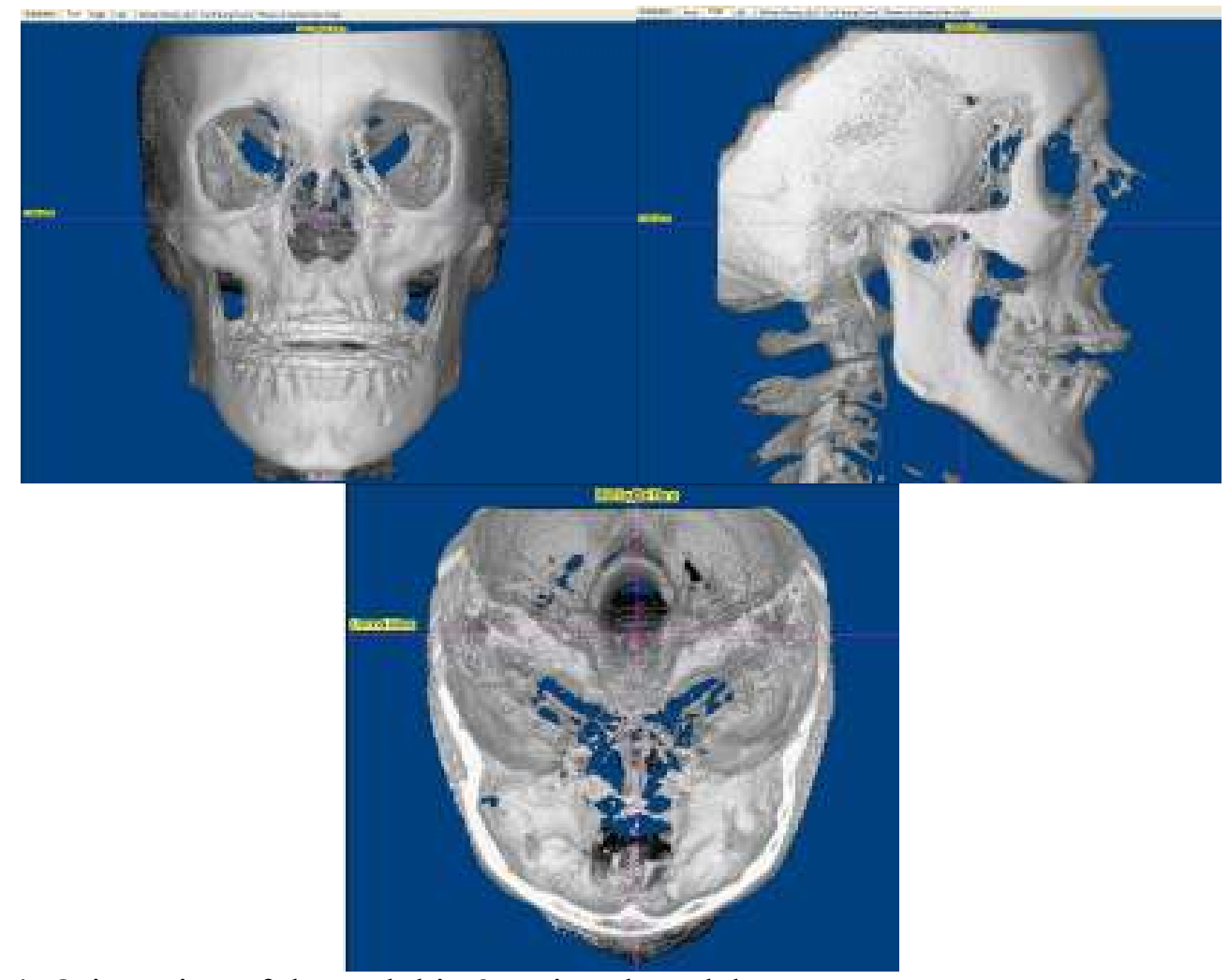

Figure 4: Orientation of the Dolphin 3D virtual model 


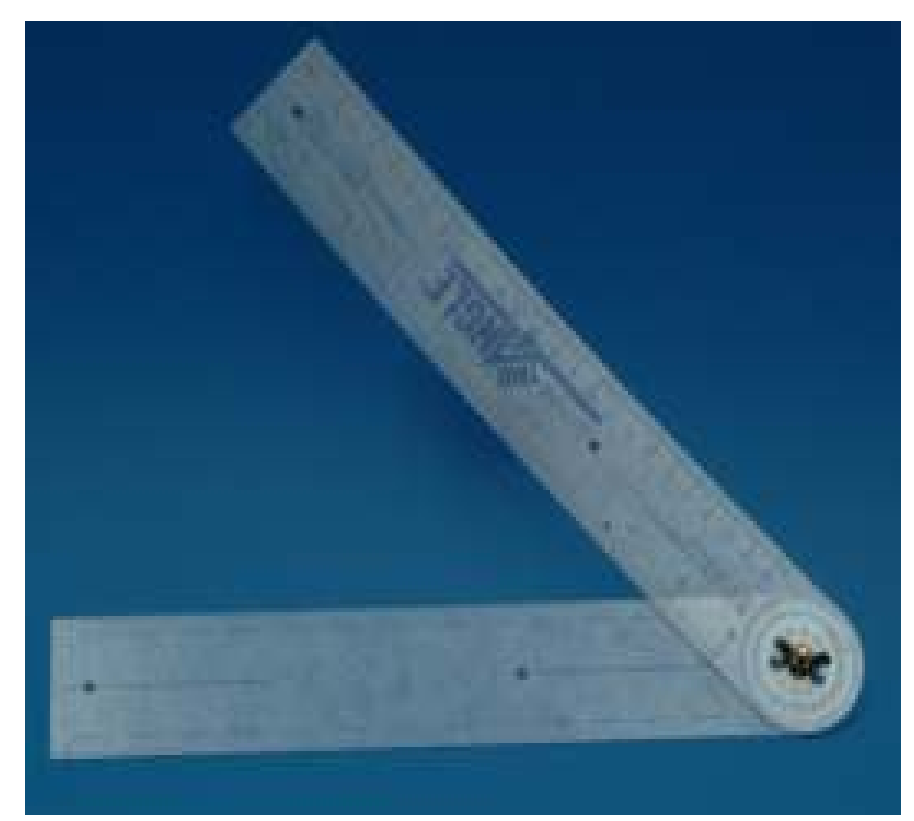

Figure 5: Angle instrument used in the study

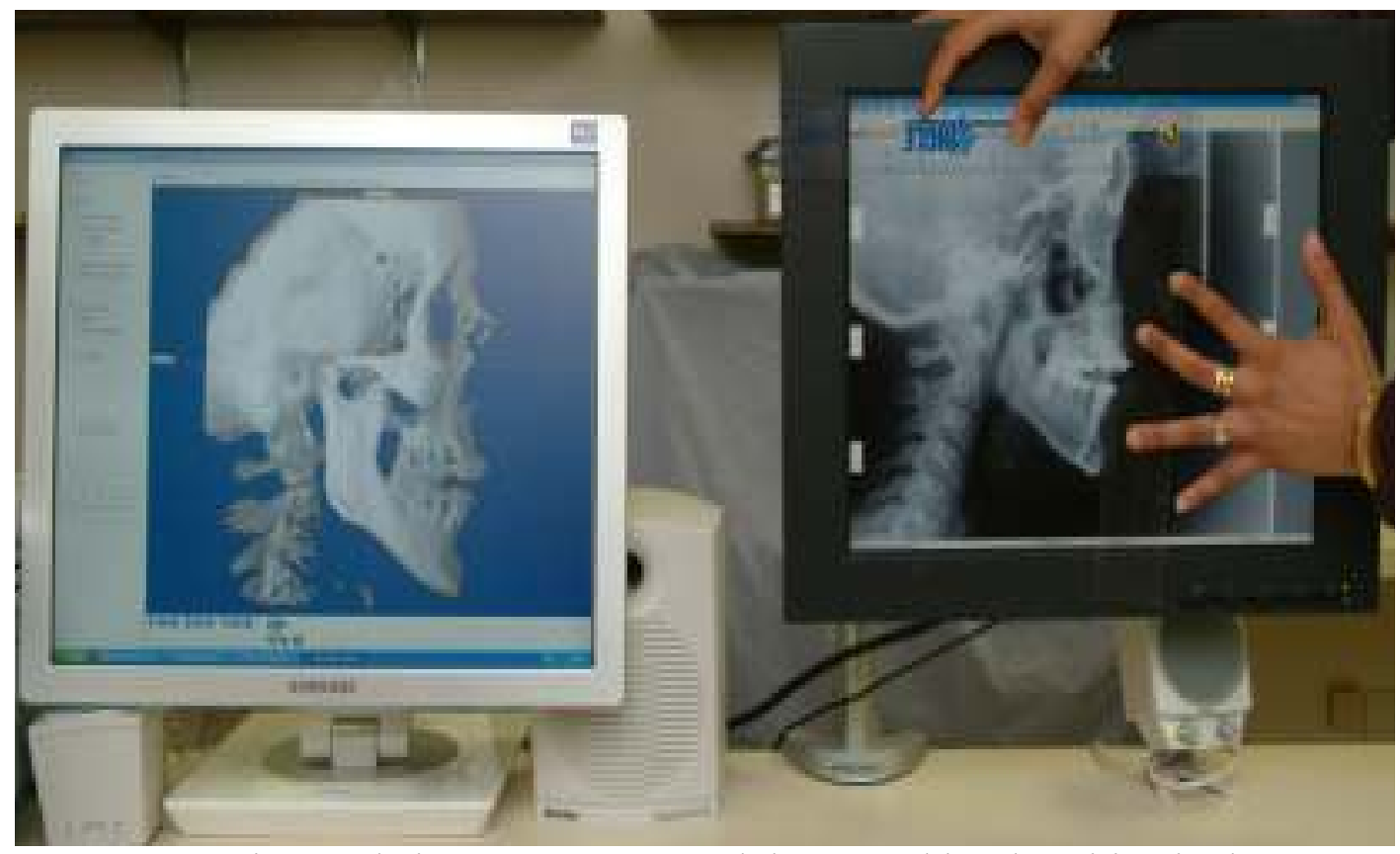

Figure 6a: Using angle instrument to record the natural head position in the conventional cephalogram 


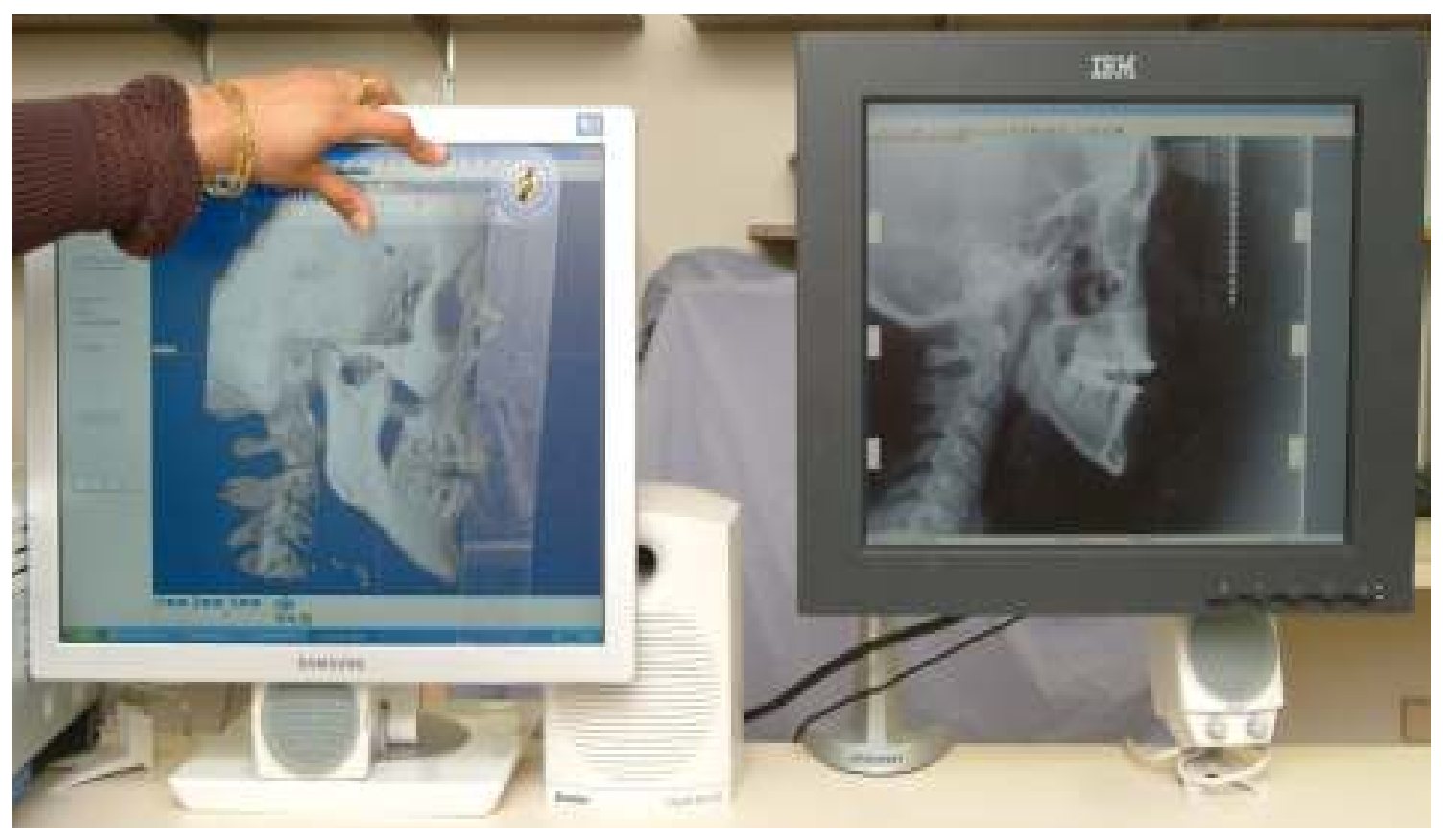

Figure 6b: Using angle instrument to simulate the natural head position in the CBCT synthesized cephalogram

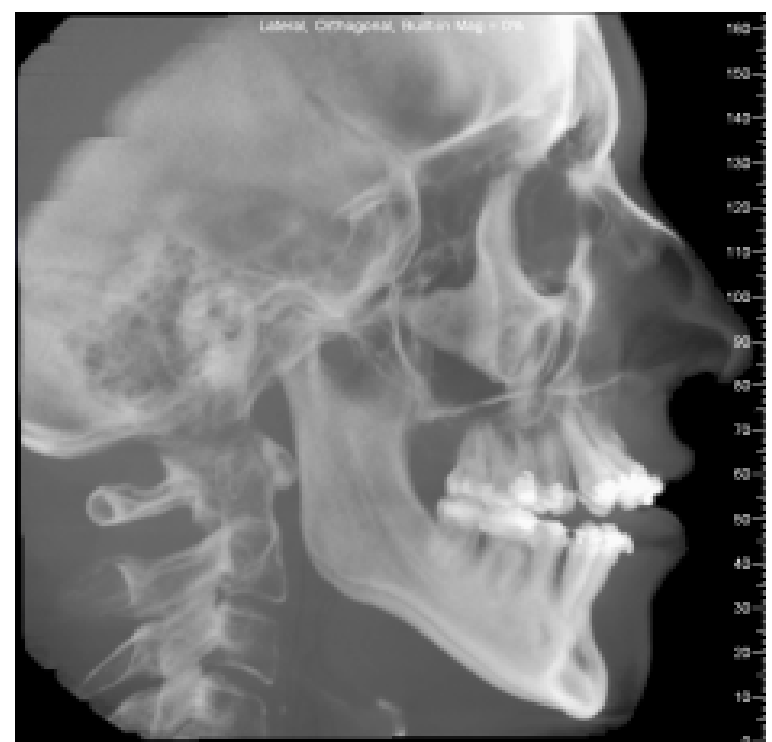

Figure: $7 \mathbf{a}$ 


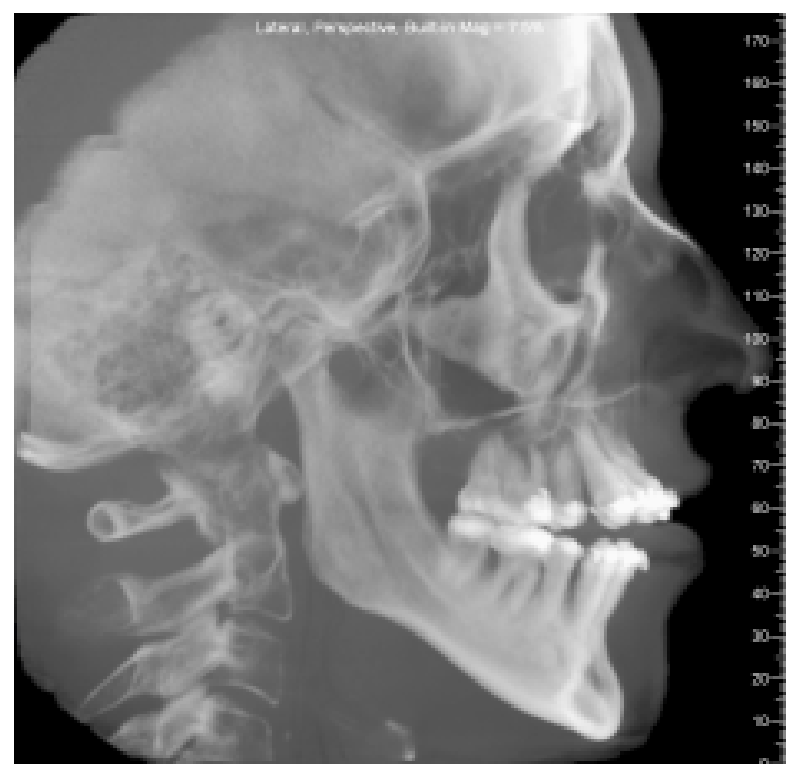

Figure $7 b$

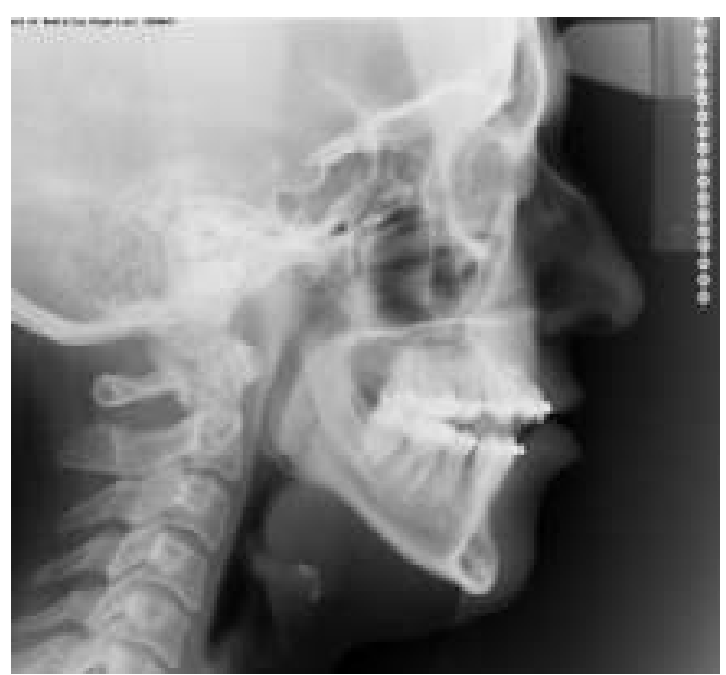

Figure 7c

Figure 7: Orthogonal CBCT projection without magnification (a); Perspective projection with $7.5 \%$ simulated magnification (b); Conventional cephalogram of skull with inherent magnification of $7.5 \%(\mathrm{c})$. 
Table 5: Measurements utilized in the study.

\begin{tabular}{|l|l|l|l|}
\hline \multicolumn{2}{|c|}{ Linear Measurements } & \multicolumn{2}{c|}{ Angular Measurements } \\
\hline LFH: & Lower Face Height (ANS-Me) & SNA: & Sella-Nasion-A \\
\hline UFH: & Upper Face Height (N-ANS) & SNB: & Sella-Nasion-B \\
\hline TFH: & Total Anterior Face Height (N-Me) & FMA: & Frankfort-Mandibular plane Angle \\
\hline MnL: & Mandibular Unit length (Co-Gn) & USN: & Upper Incisor-Sella/Nasion \\
\hline MxL: & Maxillary Unit Length (Co-ANS) & LMP: & Lower Incisor-Mandibular Plane \\
\hline AN: & A to N with respect to true vertical & & \\
\hline BN: & B to N with respect to true vertical & & \\
\hline PgN: & Pg to N with respect to true vertical & & \\
\hline OJT: & Overjet & & \\
\hline ST(LN) & $\begin{array}{l}\text { Lower lip to N with respect to true } \\
\text { vertical (Soft tissue) }\end{array}$ & & \\
\hline ST(UN) & $\begin{array}{l}\text { Upper lip to N with respect to true } \\
\text { vertical (Soft tissue) }\end{array}$ & & \\
\hline ST(PgN) & $\begin{array}{l}\text { Pg to N with respect to true vertical } \\
\text { (Soft tissue) }\end{array}$ & & \\
\hline $\begin{array}{l}\text { ANS: Anterior Nasal Spine; Me: Menton; N: Nasion; Co: Condylion; Gn: Gnathion; Pg: A: point A; B: point B; } \\
\text { Pogonion; S: Sella; Frankfort: Frankfort horizontal plane; MP: Mandibular Plane (Me-Go).ST:soft tissue } \\
\text { landmark }\end{array}$ & & & \\
\hline
\end{tabular}


Table 6: Differences between linear measurements $(\mathrm{mm})$ from three imaging modalities

\begin{tabular}{|c|c|c|c|c|c|c|}
\hline & \multicolumn{2}{|c|}{$\begin{array}{c}\text { Conventional - } \\
\text { Orthogonal CBCT }\end{array}$} & \multicolumn{2}{|c|}{$\begin{array}{c}\text { Perspective CBCT - } \\
\text { Orthogonal CBCT }\end{array}$} & \multicolumn{2}{|c|}{$\begin{array}{c}\text { Perspective CBCT - } \\
\text { Conventional }\end{array}$} \\
\hline & Mean & SD & Mean & SD & Mean & SD \\
\hline LFH & -0.95 & 1.88 & 0.04 & 1.90 & 0.99 & 2.84 \\
\hline UFH & 0.56 & 2.44 & 0.65 & 2.70 & 0.09 & 1.94 \\
\hline $\mathrm{TFH}$ & -0.80 & 2.62 & 0.42 & 3.38 & 1.23 & 3.22 \\
\hline $\mathrm{MnL}$ & -1.39 & 2.57 & -0.82 & 3.56 & 0.57 & 3.51 \\
\hline MxL & 2.21 & 4.71 & 0.43 & 5.38 & -1.78 & 4.09 \\
\hline $\mathrm{AN}$ & 1.15 & 3.59 & 0.78 & 2.55 & -0.37 & 3.41 \\
\hline $\mathrm{BN}$ & -0.26 & 4.16 & -0.03 & 2.15 & 0.23 & 4.07 \\
\hline $\mathrm{PgN}$ & -0.12 & 4.29 & 0.16 & 2.27 & 0.28 & 4.60 \\
\hline OJT & 0.25 & 1.47 & 0.08 & 0.93 & -0.17 & 1.33 \\
\hline $\mathrm{ST}(\mathrm{LN})$ & 0.76 & 3.39 & 0.03 & 1.75 & -0.73 & 3.38 \\
\hline ST(UN) & 1.45 & 3.33 & -0.15 & 1.40 & -1.61 & 3.30 \\
\hline $\mathrm{ST}(\mathrm{PgN})$ & 0.77 & 4.13 & 0.03 & 2.31 & -0.74 & 4.14 \\
\hline \multicolumn{7}{|c|}{$\begin{array}{l}\text { Conventional: conventional cephalograms adjusted for magnification } \\
\text { Perspective CBCT: synthesized cone-beam CT cephalograms with perspective projection adjusted for } \\
\text { magnification } \\
\text { Orthogonal CBCT: synthesized cone-beam CT cephalograms with orthogonal projection }\end{array}$} \\
\hline
\end{tabular}


Table 7: P-values from the paired t-test for the linear measurements from three imaging modalities.

\begin{tabular}{|c|c|c|c|}
\hline & $\begin{array}{c}\text { Conventional - } \\
\text { Orthogonal CBCT }\end{array}$ & $\begin{array}{c}\text { Perspective CBCT - } \\
\text { Orthogonal CBCT }\end{array}$ & $\begin{array}{c}\text { Perspective CBCT - } \\
\text { Conventional }\end{array}$ \\
\hline LFH & 0.01 & 0.91 & 0.06 \\
\hline UFH & 0.21 & 0.19 & 0.81 \\
\hline TFH & 0.10 & 0.49 & 0.04 \\
\hline MnL & 0.01 & 0.21 & 0.37 \\
\hline MxL & 0.01 & 0.66 & 0.02 \\
\hline AN & 0.08 & 0.10 & 0.54 \\
\hline BN & 0.73 & 0.94 & 0.74 \\
\hline $\begin{array}{l}\text { PgN } \\
\text { Perspective CBCT: synthesized cone-beam CT cephalograms with perspective projection adjusted for } \\
\text { Orthogonal CBCT: synthesized cone-beam CT cephalograms with orthogonal projection }\end{array}$ & 0.70 & 0.48 \\
\hline Bonferroni correction factor for multiple comparisons lowers the $\alpha$ value to 0.003 for a 2-tailed test.
\end{tabular}


Table 8: Differences between angular measurements (degrees) from three imaging modalities

\begin{tabular}{|c|c|c|c|c|c|c|}
\hline & \multicolumn{2}{|c|}{$\begin{array}{c}\text { Conventional - } \\
\text { Orthogonal CBCT }\end{array}$} & \multicolumn{2}{|c|}{$\begin{array}{l}\text { Perspective CBCT - } \\
\text { Orthogonal CBCT }\end{array}$} & \multicolumn{2}{|c|}{$\begin{array}{c}\text { Perspective CBCT - } \\
\text { Conventional }\end{array}$} \\
\hline & Mean & SD & Mean & SD & Mean & SD \\
\hline SNA & 0.91 & 3.06 & 0.35 & 3.31 & -0.56 & 2.31 \\
\hline SNB & -0.37 & 1.55 & -0.48 & 1.67 & -0.11 & 1.52 \\
\hline FMA & 4.09 & 3.43 & -0.27 & 2.27 & -4.36 & 3.84 \\
\hline USN & -1.29 & 7.49 & -0.35 & 6.66 & 0.94 & 5.23 \\
\hline LMP & -0.46 & 3.82 & -1.05 & 2.96 & -0.58 & 3.74 \\
\hline \multicolumn{7}{|c|}{$\begin{array}{l}\text { Conventional: conventional cephalograms adjusted for magnification } \\
\text { Perspective CBCT: synthesized cone-beam CT cephalograms with perspective projection adjusted for } \\
\text { magnification } \\
\text { Orthogonal CBCT: synthesized cone-beam CT cephalograms with orthogonal projection }\end{array}$} \\
\hline
\end{tabular}


Table 9: P-values from the paired t-test for the angular measurements of three imaging modalities.

\begin{tabular}{|c|c|c|c|}
\hline & $\begin{array}{c}\text { Conventional - } \\
\text { Orthogonal CBCT }\end{array}$ & $\begin{array}{c}\text { Perspective CBCT - } \\
\text { Orthogonal CBCT }\end{array}$ & $\begin{array}{c}\text { Perspective CBCT - } \\
\text { Conventional }\end{array}$ \\
\hline SNA & 0.11 & 0.57 & 0.19 \\
\hline SNB & 0.20 & 0.12 & 0.68 \\
\hline FMA & $<0.0001^{*}$ & 0.52 & 0.33 \\
\hline USN & 0.35 & 0.77 & 0.40 \\
\hline LMP & 0.50 & 0.06 & $<1^{*}$ \\
\hline $\begin{array}{l}\text { Conventional: conventional cephalograms adjusted for magnification } \\
\text { Perspective CBCT: synthesized cone-beam CT cephalograms with perspective projection adjusted for } \\
\text { magnification } \\
\text { Orthogonal CBCT: synthesized cone-beam CT cephalograms with orthogonal projection } \\
\text { Bonferroni correction factor for multiple comparisons lowers the p-value to 0.003. }\end{array}$ \\
\hline
\end{tabular}




\section{References}

1. Ahlqvist J, Eliasson S, Welander U. The effect of projection errors on cephalometric length measurements. Eur J Orthod. 1986; 8: 141-148.

2. Baumrind S, Frantz RC. The reliability of head film measurements. 1. Landmark identification. Am J Orthod. 1971; 60: 111-127.

3. Baumrind S, Frantz RC. The reliability of head film measurements. 2. Conventional angular and linear measures. Am J Orthod. 1971; 60: 505-517.

4. Danforth RA, Dus I, Mah J. 3-D volume imaging for dentistry: a new dimension. $J$ Calif Dent Assoc. 2003; 31: 817-823.

5. Ekestubbe A, Thilander A, Grondahl K, Grondahl HG. Absorbed doses from computed tomography for dental implant surgery: comparison with conventional tomography. Dentomaxillofac Radiol. 1993; 22: 13-17.

6. Ludlow JB, Davies-Ludlow LE, Brooks SL. Dosimetry of two extraoral direct digital imaging devices: NewTom cone beam CT and Orthophos Plus DS panoramic unit. Dentomaxillofac Radiol. 2003; 32: 229-234.

7. Sukovic P. Cone beam computed tomography in craniofacial imaging. Orthod Craniofac Res. 2003; 6 Suppl 1: 31-6; discussion 179-82.

8. Farman AG, Scarfe WC. Development of imaging selection criteria and procedures should precede cephalometric assessment with cone-beam computed tomography. Am J Orthod Dentofacial Orthop. 2006; 130: 257-265.

9. Cevidanes LH, Styner MA, Proffit WR. Image analysis and superimposition of 3dimensional cone-beam computed tomography models. Am J Orthod Dentofacial Orthop. 2006; 129: 611-618.

10. Cevidanes LH, Bailey LJ, Tucker GR,Jr, Styner MA, Mol A, Phillips CL, Proffit WR, Turvey T. Superimposition of 3D cone-beam CT models of orthognathic surgery patients. Dentomaxillofac Radiol. 2005; 34: 369-375.

\section{Kumar V, Ludlow JB, Mol A, Cevidanes LH, ". Comparison of Conventional and} Cone Beam CT synthesized Cephalograms. DMFR. In press.

12. Waitzman AA, Posnick JC, Armstrong DC, Pron GE. Craniofacial skeletal measurements based on computed tomography: Part II. Normal values and growth trends. Cleft Palate Craniofac J. 1992; 29: 118-128.

13. Athanasiou AE, Miethke R, Van Der Meij AJ. Random errors in localization of landmarks in postero-anterior cephalograms. Br J Orthod. 1999; 26: 273-284. 
14. Ludlow JB, Laster WS, See M, Bailey LJ, Hershey HG. Accuracy of measurements of mandibular anatomy in cone beam computed tomography images. Oral Surg Oral Med Oral Pathol Oral Radiol Endod. 2007; 103: 534-542.

15. Chate RA. Cephalometric landmark identification within the petrous temporal region. $\mathrm{Br}$ J Orthod. 1987; 14: 33-41.

16. Adenwalla ST, Kronman JH, Attarzadeh F. Porion and condyle as cephalometric landmarks--an error study. Am J Orthod Dentofacial Orthop. 1988; 94: 411-415.

17. Lascala CA, Panella J, Marques MM. Analysis of the accuracy of linear measurements obtained by cone beam computed tomography (CBCT-NewTom). Dentomaxillofac Radiol. 2004; 33: 291-294.

18. Yoon YJ, Kim KS, Hwang MS, Kim HJ, Choi EH, Kim KW. Effect of head rotation on lateral cephalometric radiographs. Angle Orthod. 2001; 71: 396-403.

19. Ferrario VF, Sforza C, Germano D, Dalloca LL, Miani A,Jr. Head posture and cephalometric analyses: an integrated photographic/radiographic technique. Am J Orthod Dentofacial Orthop. 1994; 106: 257-264.

20. Malkoc S, Sari Z, Usumez S, Koyuturk AE. The effect of head rotation on cephalometric radiographs. Eur J Orthod. 2005; 27: 315-321.

21. Moorrees CF. Natural head position--a revival. Am J Orthod Dentofacial Orthop. 1994; 105: 512-513.

22. Ferrario VF, Sforza C, Germano D, Dalloca LL, Miani A,Jr. Head posture and cephalometric analyses: an integrated photographic/radiographic technique. Am J Orthod Dentofacial Orthop. 1994; 106: 257-264.

23. Lundstrom A, Lundstrom F, Lebret LM, Moorrees CF. Natural head position and natural head orientation: basic considerations in cephalometric analysis and research. Eur $J$ Orthod. 1995; 17: 111-120. 


\section{DISCUSSION AND CONCLUSIONS}

Cephalometry is a valuable tool for diagnosis of skeletal imbalance, growth assessment, response to treatment, and long-term stability following orthodontic treatment. Lateral and frontal cephalograms together with facial photographs are currently the main diagnostic imaging modalities for the assessment of craniofacial hard and soft tissue morphology. But the magnification and distortion inherent to conventional transmission radiography makes it difficult to accurately assess the patient's anatomy.

While the potential advantages of 3D CBCT imaging are evident, ${ }^{26,}{ }^{27}$ quantitative assessment of the 3D facial form requires validation through comparison with traditional methods. Clinicians will more readily accept advances in CBCT imaging of the maxillofacial skeleton if images can be synthesized that are similar to the ones they are familiar with and have used for several decades. ${ }^{28}$ The current study was undertaken to emphasize the fact that traditional radiographic projections can be synthesized from CBCT volumes and traditional cephalometric analysis can be done on these synthesized views with similar precision and accuracy. While much work is needed to demonstrate the added value of CBCT in standard orthodontic cases, it is not known whether data obtained from synthesized CBCT views can be compared with current population norms and existing databases obtained from conventional cephalograms. Because synthesized views discard much of the $3 \mathrm{D}$ information embedded in CBCT image volumes, the demonstration of correspondence between CBCT and conventional radiography would be useful during this transition period. 
This study utilized skull measurements as the gold standard to assess the accuracy of three mid-sagittal image measurements; while patient data was used to assess soft tissue landmarks, which could not be assessed in the dry skulls. The conventional imaging modality under-estimates actual skull dimensions while the perspective CBCT over-estimates skull dimensions. Orthogonal CBCT provided measurements closest to the actual skull measurements and was significantly more precise than the other image modalities as assessed by absolute difference of measurement. The results of this study also show that the linear measurements of the three imaging modalities were not statistically different except for Mandibular unit length (MnL). This is consistent with the observation of Lascala and coauthors that $\mathrm{CBCT}$ technique is reliable for use in a variety of clinical situations where linear measurements between anatomical sites are required. ${ }^{29}$

All the angular measurements were also not statically significant except for one angular measurement Frankfort-Mandibular plane Angle (FMA). Although measurement differences related to projective distortion of bilateral structures were hypothesized, no significant difference for measurements involving Condylion, Gonion, Porion, or Orbitale were seen between Orthogonal $\mathrm{CBCT}$, perspective $\mathrm{CBCT}$, and conventional cephalometric images with the exception of Mandibular Length (MnL), and FMA.

Every system has various sources of noise. In this study, only projection geometry as the source of noise was explored, but other sources like landmark definition, observer variability in landmark identification and the ability to digitize the landmarks were not investigated. The cephalometric literature reveals that landmarks like condylion, porion and gonion, which are used to define the frankfort horizontal plane and the mandibular plane, have greater margins of error. ${ }^{30}$ The literature shows that superimposition of the bilateral 
middle ear and other temporal fosse structures make the identification of anatomical porion difficult. ${ }^{31}$.The landmarks like gonion and condylion are located on the curvature and thus are difficult to identify accurately. ${ }^{32}$ There is also a difference in the superimposition anatomy in the orthogonal and the perspective projection. These various sources of noise might have influenced some of the measurements.

Another potential source for variation in perspective CBCT cephalograms is the reference, which the reconstruction algorithm uses for determining a midsagittal plane. If the center of the image volume is used, this may not coincide with the anatomic midsagittal plane. Because a cephalostat is not used in CBCT imaging, the patient position may be eccentric with respect to the volume. Patient positioning is considered critical for cephalometric analysis. The conventional cephalograms produced in the UNC School of Dentistry are taken in natural head position using a cephalostat consisting of ear rods and a nasal positioner. Natural head position is the position taken by the head when a subject is looking at a distant point at eye level. ${ }^{33-35}$ The purpose of the cephalostat is to minimize projection errors caused by head rotation around the vertical, transverse, and anteroposterior axes. The variations in patient position may lead to variation in cephalometric measurements. ${ }^{36}$ Although 3D measurements of CBCT volumes are free from the influence of patient position during image acquisition, ${ }^{37}$ the orientation of the secondary reconstruction of the volume directly impacts the projection of anatomy in synthesized 2D cephalometric views. Therefore to remove the potential source of measurement error in the synthesized views associated with errors in skull positioning due to faulty positioning of the cephalostat or faulty positioning of the patient within the cephalostat, the orientation of the CT volume was corrected by iterative adjustment and reassessment. Natural head position in patient data 
was simulated by using the angle instrument. The alignment of the transporionic axis using the 3D rendered volumes was sufficiently accurate to preclude differences in identification and measurement of the landmarks used in this study. The ability to reorient the volume means that cephalostat errors, common to conventional cephalometry, can be eliminated in equivalent $\mathrm{CBCT}$ projections.

Location of 2D landmarks on the skull and the actual 3D CBCT model still poses a challenge. ${ }^{38,39}$ While viewing anatomy in 3 dimensions; it is evident that precise landmarks often do not exist. ${ }^{40}$ The sharp edges seen in $2 \mathrm{D}$ projections are replaced by surfaces and curves in the $3 \mathrm{D}$ rendering. For example, locating Porion $(\mathrm{P})$ on the $\mathrm{CBCT}$ synthesized projections was often a challenge. While ear rods used in conventional cephalograms indicate the location of the external auditory meatus, the anatomic porion is different from the external opening. Various authors ${ }^{41-43}$ suggest advances towards studies of curves or surfaces in $3 \mathrm{D}$, referring to tens of thousands of $3 \mathrm{D}$ points to define geometry. Netherway and coauthors ${ }^{44}$ and Schaefer and coauthors ${ }^{45}$ used semilandmarks on the surface to incorporate information about deficient direction in landmark definition into the analysis of 3D data. Richtsmeier J.T and coauthors ${ }^{46}$ evaluated the precision and repeatability of locating anatomic landmarks in three dimensions on CT slice.

The statistically significant difference between the values of two of the angle measurements of synthesized projections compared to conventional lateral views requires further investigation. Although those differences were relatively small, they could be clinically relevant. In general, the results of this study suggest that both types of synthesized projections can be used with a precision and accuracy similar to conventional cephalograms and those cephalometric views generated from CBCT volumes may be used in place of 
conventional cephalometric images. If $\mathrm{CBCT}$ volumes are acquired, additional conventional cephalograms may be avoided to reduce $\mathrm{x}$-ray exposure and examination expense. 


\section{BIBLIOGRAPHY}

1. Baumrind S, Frantz RC. The reliability of head film measurements. 2. Conventional angular and linear measures. Am J Orthod. 1971;60:505-517.

2. Grayson B, Cutting C, Bookstein FL, Kim H, McCarthy JG. The three-dimensional cephalogram: theory, technique, and clinical application. Am J Orthod Dentofacial Orthop. 1988; 94: 327-337.

3. Ahlqvist J, Eliasson S, Welander U. The effect of projection errors on cephalometric length measurements. Eur J Orthod. 1986; 8: 141-148.

4. Yoon YJ, Kim KS, Hwang MS, Kim HJ, Choi EH, Kim KW. Effect of head rotation on lateral cephalometric radiographs. Angle Orthod. 2001; 71: 396-403.

5. Chen YJ, Chen SK, Chang HF, Chen KC. Comparison of landmark identification in traditional versus computer-aided digital cephalometry. Angle Orthod. 2000; 70: 387392.

6. Chen YJ, Chen SK, Huang HW, Yao CC, Chang HF. Reliability of landmark identification in cephalometric radiography acquired by a storage phosphor imaging system. Dentomaxillofac Radiol. 2004; 33: 301-306.

7. Halazonetis DJ. From 2-dimensional cephalograms to 3-dimensional computed tomography scans. Am J Orthod Dentofacial Orthop. 2005; 127: 627-637.

8. Forsyth DB, Shaw WC, Richmond S, Roberts CT. Digital imaging of cephalometric radiographs, Part 2: Image quality. Angle Orthod. 1996; 66: 43-50.

9. Geelen W, Wenzel A, Gotfredsen E, Kruger M, Hansson LG. Reproducibility of cephalometric landmarks on conventional film, hardcopy, and monitor-displayed images obtained by the storage phosphor technique. Eur J Orthod. 1998; 20: 331-340.

10. Santoro M, Jarjoura K, Cangialosi TJ. Accuracy of digital and analogue cephalometric measurements assessed with the sandwich technique. Am J Orthod Dentofacial Orthop. 2006; 129: 345-351.

11. Halazonetis DJ. Morphometrics for cephalometric diagnosis. Am J Orthod Dentofacial Orthop. 2004; 125: 571-581. 
12. Gliddon MJ, Xia JJ, Gateno J, Wong HT, Lasky RE, Teichgraeber JF, Jia X, Liebschner MA, Lemoine JJ. The accuracy of cephalometric tracing superimposition. J Oral Maxillofac Surg. 2006; 64: 194-202.

15. Danforth RA, Dus I, Mah J. 3-D volume imaging for dentistry: a new dimension. $J$ Calif Dent Assoc. 2003; 31: 817-823.

16. Swennen GR, Schutyser F. Three-dimensional cephalometry: spiral multi-slice vs conebeam computed tomography. Am J Orthod Dentofacial Orthop. 2006; 130: 410-416.

17. Cavalcanti MG, Rocha SS, Vannier MW. Craniofacial measurements based on 3D-CT volume rendering: implications for clinical applications. Dentomaxillofac Radiol. 2004; 33: $170-176$.

18. Ekestubbe A, Thilander A, Grondahl K, Grondahl HG. Absorbed doses from computed tomography for dental implant surgery: comparison with conventional tomography. Dentomaxillofac Radiol. 1993; 22: 13-17.

19. Scaf G, Lurie AG, Mosier KM, Kantor ML, Ramsby GR, Freedman ML. Dosimetry and cost of imaging osseointegrated implants with film-based and computed tomography. Oral Surg Oral Med Oral Pathol Oral Radiol Endod. 1997; 83: 41-48.

20. Sukovic P. Cone beam computed tomography in craniofacial imaging. Orthod Craniofac Res. 2003; 6 Suppl 1: 31-6; discussion 179-82.

21. Farman AG, Scarfe WC. Development of imaging selection criteria and procedures should precede cephalometric assessment with cone-beam computed tomography. Am $J$ Orthod Dentofacial Orthop. 2006; 130: 257-265.

22. Ludlow JB, Davies-Ludlow LE, Brooks SL. Dosimetry of two extraoral direct digital imaging devices: NewTom cone beam CT and Orthophos Plus DS panoramic unit. Dentomaxillofac Radiol. 2003; 32: 229-234.

23. Cevidanes LH, Bailey LJ, Tucker GR,Jr, Styner MA, Mol A, Phillips CL, Proffit WR, Turvey T. Superimposition of 3D cone-beam CT models of orthognathic surgery patients. Dentomaxillofac Radiol. 2005; 34: 369-375.

24. Cevidanes LH, Styner MA, Proffit WR. Image analysis and superimposition of 3dimensional cone-beam computed tomography models. Am J Orthod Dentofacial Orthop. 2006; 129: 611-618.

25. Baumrind S, Frantz RC. The reliability of head film measurements. 1. Landmark identification. Am J Orthod. 1971; 60: 111-127.

26. Hassfeld S, Muhling J. Computer assisted oral and maxillofacial surgery--a review and an assessment of technology. Int J Oral Maxillofac Surg. 2001; 30: 2-13. 
27. Nakasima A, Terajima M, Mori N, Hoshino Y, Tokumori K, Aoki Y, Hashimoto S. Three-dimensional computer-generated head model reconstructed from cephalograms, facial photographs, and dental cast models. Am J Orthod Dentofacial Orthop. 2005; 127: 282-292.

28. Halazonetis DJ. From 2-dimensional cephalograms to 3-dimensional computed tomography scans. Am J Orthod Dentofacial Orthop. 2005; 127: 627-637.

29. Lascala CA, Panella J, Marques MM. Analysis of the accuracy of linear measurements obtained by cone beam computed tomography (CBCT-NewTom). Dentomaxillofac Radiol. 2004; 33: 291-294.

30. Athanasiou AE, Miethke R, Van Der Meij AJ. Random errors in localization of landmarks in postero-anterior cephalograms. Br J Orthod. 1999; 26: 273-284.

31. Chate RA. Cephalometric landmark identification within the petrous temporal region. $\mathrm{Br}$ J Orthod. 1987; 14: 33-41.

32. Adenwalla ST, Kronman JH, Attarzadeh F. Porion and condyle as cephalometric landmarks--an error study. Am J Orthod Dentofacial Orthop. 1988; 94: 411-415.

33. Ferrario VF, Sforza C, Germano D, Dalloca LL, Miani A,Jr. Head posture and cephalometric analyses: an integrated photographic/radiographic technique. Am J Orthod Dentofacial Orthop. 1994; 106: 257-264.

34. Moorrees CF. Natural head position--a revival. Am J Orthod Dentofacial Orthop. 1994; 105: 512-513.

35. Lundstrom A, Lundstrom F, Lebret LM, Moorrees CF. Natural head position and natural head orientation: basic considerations in cephalometric analysis and research. Eur $J$ Orthod. 1995; 17: 111-120.

36. Malkoc S, Sari Z, Usumez S, Koyuturk AE. The effect of head rotation on cephalometric radiographs. Eur J Orthod. 2005; 27: 315-321.

37. Laster WS, Ludlow JB, Bailey LJ, Hershey HG. Accuracy of measurements of mandibular anatomy and prediction of asymmetry in panoramic radiographic images. Dentomaxillofac Radiol. 2005; 34: 343-349.

38. Baumrind S, Moffitt F. Mapping the skull in 3-d. J Calif Dent Assoc. 1972; 48: 22-31.

39. Harrell WE,Jr, Hatcher DC, Bolt RL. In search of anatomic truth: 3-dimensional digital modeling and the future of orthodontics. Am J Orthod Dentofacial Orthop. 2002; 122: 325-330.

40. Glat PM, Freund RM, Spector JA, Levine J, Noz M, Bookstein FL, McCarthy JG, Cutting CB. A classification of plagiocephaly utilizing a three-dimensional computer analysis of cranial base landmarks. Ann Plast Surg. 1996; 36: 469-474. 
41. Mafart B, Guipert G, de Lumley MA, Subsol G. Three-dimensional computer imaging of hominid fossils: a new step in human evolution studies. Can Assoc Radiol J. 2004; 55: 264-270.

42. Kragskov J, Bosch C, Gyldensted C, Sindet-Pedersen S. Comparison of the reliability of craniofacial anatomic landmarks based on cephalometric radiographs and threedimensional CT scans. Cleft Palate Craniofac J. 1997; 34: 111-116.

43. Lagravere MO, Major PW. Proposed reference point for 3-dimensional cephalometric analysis with cone-beam computerized tomography. Am J Orthod Dentofacial Orthop. 2005; 128 : 657-660.

44. Netherway DJ, Abbott AH, Gulamhuseinwala N, McGlaughlin KL, Anderson PJ, Townsend GC, David DJ. Three-Dimensional Computed Tomography Cephalometry of Plagiocephaly: Asymmetry and Shape Analysis. Cleft Palate Craniofac J. 2006; 43: 201210.

45. Schaefer K, Lauc T, Mitteroecker P, Gunz P, Bookstein FL. Dental arch asymmetry in an isolated Adriatic community. Am J Phys Anthropol. 2006; 129: 132-142.

46. Richtsmeier JT, Paik CH, Elfert PC, Cole TM,3rd, Dahlman HR. Precision, repeatability, and validation of the localization of cranial landmarks using computed tomography scans. Cleft Palate Craniofac J. 1995; 32: 217-227. 